Article

\title{
Study on Passive Ventilation and Cooling Strategies for Cold Lanes and Courtyard Houses-A Case Study of Rural Traditional Village in Shaanxi, China
}

\author{
Xingbo Yao ${ }^{1, *}{ }^{\mathbb{D}}$, Bart J. Dewancker ${ }^{1}\left(\mathbb{D}\right.$, Yuang Guo ${ }^{1}$, Shuo Han ${ }^{2}$ and Juan $\mathrm{Xu}^{3}$ \\ 1 Faculty of Environmental Engineering, The University of Kitakyushu, Kitakyushu 808-0135, Japan; \\ bart@kitakyu-u.ac.jp (B.J.D.); gya900328@gmail.com (Y.G.) \\ 2 School of Communication Engineering, Xidian University, Xi'an 710071, China; hanshuo1991sure@163.com \\ 3 School of Architecture, Chang'an University, Xi'an 710061, China; xujuan0626@chd.edu.cn \\ * Correspondence: yaohanhome@gmail.com; Tel.: +81-90-2968-8668
}

Received: 14 September 2020; Accepted: 15 October 2020; Published: 20 October 2020

check for updates

\begin{abstract}
China's research on and specific implementation of energy saving for buildings are mainly concentrated in urban areas, but according to 2016 statistics, the rural population accounts for $42.65 \%$ of the total population, so rural housing has considerable energy-saving potential. However, the degree of attention to the energy consumption of rural houses needs to be improved. Regarding the research on and implementation of passive energy-saving strategies for residences, compared with centralized urban high-rise residences, rural residences mainly have independent courtyards, with a flexible layout and easier transformation. In this study, a system that uses the common cold lanes in traditional villages and buildings' exterior walls was constructed, and the indoor spaces of courtyard buildings in southern Shaanxi were completely passively cooled in summer. This system can be completely separated from the supply of artificial energy by relying on the accumulation and buoyancy effects of air in patios and cold lanes and the hot-pressure ventilation in buildings to cool the buildings and greatly improve indoor ventilation efficiency. As the building is ventilated and cooled, the air wall formed in the system can effectively prevent direct contact between the outdoor and indoor temperatures and reduce the impact of thermal wall radiation on the interior. In previous studies on the passive design of courtyard houses, scholars considered the effect of thermal wall radiation on indoor temperature in simulations. Therefore, in this study, we also separately calculated whether to consider the difference between the situation with and without wall heat radiation (WHR) when simulating thermal conversion. The final results show that when the cooling system was adopted, the annual cooling load of the whole building was $4786.494 \mathrm{~kW} \cdot \mathrm{h}$ without WHR. However, with WHR, the cooling load reduction was $2989.128 \mathrm{~kW} \cdot \mathrm{h}$, a difference of $1797.336 \mathrm{~kW} \cdot \mathrm{h}$.
\end{abstract}

Keywords: numerical simulation; residential passive cooling; cold lane; courtyard house

\section{Introduction}

\subsection{Motivation}

The world's population reached 7.442 billion in 2016 [1]. Industry, agriculture, transport, and infrastructure need to accelerate to meet the needs of this huge population. With the substantial population growth, total energy consumption is also increasing. Commercial, residential, and public energy consumption accounts for approximately 30-40\% of global energy consumption [2]. Among the various uses of energy, its use in buildings has become one of the most energy-consuming practices in the world [3]. Currently, carbon emissions caused by the construction and use of buildings will increase by $50 \%$ by 2050 [4]. Increased carbon emissions is an important cause of global warming. 
In this environment of global warming, the requirements for indoor cooling are gradually increasing [5]. In recent years, the rise in sales of air-conditioners, which can be used to cool effectively, has led to a vicious cycle of higher carbon emissions [6]. This situation is more obvious in developing countries, because some of them are in the process of large-scale urbanization. China is a typical example. In China, energy consumption related to construction accounts for $44.7 \%$ of the total energy consumption each year, and carbon emissions account for about $30 \%$ of the national total [7]. However, these data are still rising. It is estimated that by 2050, China's building energy consumption and carbon emissions will be double the current levels [8].

Under the influence of the rapid development of urbanization, the energy consumption of single families is also increasing annually, and as early as 2011, individual lifetime energy consumption exceeded the total energy consumption of various factories in China [9]. Based on this phenomenon, the issue of energy-saving for family residences has attracted the attention of domestic and foreign scholars. In recent years, China and most countries in Asia have focused on researching various energy-efficient houses, such as low-carbon, green energy-saving, and smart buildings [10]. However, even though scholars and architects have made a lot of effort in this area, the expected goals have not been fully achieved [11].

Many scholars have paid attention to the energy-saving problem of urban residential buildings. According to the standards of different cities, relevant building codes, laws, and regulations have been formulated to limit certain amounts of energy consumption. However, most villages have a vague awareness of residential energy savings. As of 2016, the rural population in China accounted for $42.65 \%$ of the total population [12], so the energy-saving potential of rural houses is also considerable. With the development of the rural economy in China in recent years, housing conditions and quality of life have gradually improved along with the increase in energy consumption. From another perspective, rural residences are essentially different from urban residences. Urban residences are mostly centralized high-rise buildings, while rural residences are mainly independent courtyard buildings. Courtyard residences are usually centered around a patio and surrounded by four buildings. Passive energy-saving in urban high-rise buildings is more difficult, because once the building is completed, the difficulty of renovating will increase significantly. As for independent courtyard houses in the countryside, reconstruction requires relatively less energy, time, and cost, and can be conducted with great freedom [13]. Moreover, rural houses are closer to nature and can make more effective use of passive energy-saving factors brought by the surrounding natural environment. In order to improve the comfort of indoor living in the countryside, this study focuses on establishing a completely new system for the purpose of passive ventilation and cooling of courtyard houses in summer.

According to the current situation of residential buildings in China's rural areas compared with urban areas, there are large differences in basic facilities, with high-energy consumption and low utilization rates. They have a single ventilation method, low clean energy usage, insufficient indoor thermal comfort, and a lack of corresponding industry technical standards [14]. Therefore, it is necessary to apply the related technology and experience of passive energy saving for modern buildings in traditional courtyard-style buildings. However, from the perspectives of protecting regional characteristics, conforming to nature, inheriting culture, improving living quality, and protecting the ecological environment, traditional residential courtyards have their own unique characteristics, which are precisely what modern architecture lacks [15]. With the continuous changing of the social background, modern architecture continues to develop rapidly toward a deeper level, mainly including aspects such as architectural composition systems, material changes, spatial forms, and traditional cultural development [16]. However, due to the inadequacy of related theories and the abuse of technology, the current architecture in the process of transformation has shown the problems of ignoring characteristic regional cultures, abandoning ecological advantages, and adopting uniform design techniques [17]. Therefore, while exploring how to design passive energy-saving equipment in combination with local climate and environmental conditions for traditional residential houses, it is also necessary to introduce ecological energy-saving concepts into modern architectural design, 
which also has practical value. In terms of academic value, proposing an optimization strategy for a passive energy-saving system for traditional residential buildings also provides some references for future research of modern residential buildings. This has great practical significance for the sustainable development of the new generation of modern rural residential buildings.

\subsection{Previous Study}

Cold lane ventilation is an integral part of the ventilation in urban canyons. In densely populated cities, the possibility that cold lanes exist is higher due to the shortage of land and the small spaces between buildings. Building spacing is a very important factor that urban planners and architects need to consider, because for a given building height, a larger space will induce more wind in the urban canyon, thereby improving the ventilation process [18]. Chen [19] conducted a large-scale outdoor measurement in Guangzhou, China, in the summer of 2017, and suggested that the street aspect ratio and urban heat storage largely determine the urban thermal environment. This research provides direct evidence for how urban structures affect the urban climate, and also suggests the possibility of controlling the outdoor thermal environment by optimizing urban forms and heat storage. Ai [20] used a computational fluid dynamics (CFDs) simulation to study the unilateral natural ventilation induced by wind in buildings near a long street canyon with vertical wind. This research improved the understanding of natural ventilation of urban buildings, providing information for urban planning and building design. In order to improve the heat dissipation in forced convection, Allegrini [21] studied different roof shapes and heights and changed the lengths of street canyon buildings. The results showed that lateral flow can be found in street canyons with uneven building heights, and the air temperature in street canyons is reduced due to improved ventilation. Hadavi [22] proposed that the layout of urban communities will affect the wind flow pattern and permeability in the built environment, and ultimately affect the local thermal comfort and energy consumption of buildings. The penetration rate of wind in low-rise residential buildings was quantified by using CFDs.

Looking at the passive design of courtyard buildings, Toe [23] investigated local passive cooling technology, proposed potential applications to improve the indoor thermal comfort of modern brick houses with natural ventilation in Malaysia, and discussed the potential passive cooling technology of brick houses, including night ventilation, roof or ceiling insulation, window and wall shading, a small courtyard concept, microclimate change, and urban heat island mitigation. Dabaieh [24] described the design of a passive refugee house. The scheme used three main passive heating and cooling solutions (earth-air heat exchanger, Trombe wall, and green wall) to suit the Swedish climate. This research was implemented in an urban life laboratory in Lund, Sweden, to verify the simulation results by monitoring the occupancy for 12 months. Dili [25] continuously monitored indoor and outdoor temperature environments by using a customized instrument called a building evaluation system. The thermal comfort parameters of traditional local buildings were quantitatively analyzed. The results showed that the natural passive control system could provide a comfortable indoor environment, regardless of the outdoor climate conditions.

The research of Ding [26] showed that over a 12-month period, the heating energy consumption of modern buildings in China was generally better than in historic buildings, but the cooling energy consumption was much higher. However, historic buildings outperformed modern buildings in terms of energy consumption and carbon analysis. If traditional buildings are replaced with modern energy-efficient buildings, the energy used to construct these buildings will take about 18-41 years to recover. $\mathrm{Xu}$ [27] focused on analyzing the characteristics of traditional houses in the Qinba Mountains, selecting two typical houses built with brick and soil, and monitored and simulated the indoor heat, light, and ventilation environment in summer and winter. This study also summarized the advantages and disadvantages of the residential physical environment in coping with climate characteristics. The results showed that traditional native houses could adapt to the local climate well in summer, but in winter, the indoor thermal comfort needs to be further improved. Finally, effective climate adaptation strategies for traditional dwellings have been proposed, such as natural ventilation, heat preservation, 
and thermal buffer space. Zhang [28] transformed Sichuan Tibetan houses in cold valleys at high altitudes into research objects, adopted T-WALL as a passive heating scheme. The total annual energy consumption of Tibetan houses with the best combination could be reduced by about $72 \%$.

On the basis of understanding urban canyon wind and the passive design of courtyards, how to effectively use urban canyon wind to improve the performance of buildings and combine the two for passive energy-saving design has also become a focus of scholars. Mitterboeck [29] assessed the microclimate of an urban canyon where there were several different environments. The purpose of this research was to explore whether plants in a city could make identifiable differences in surrounding buildings. Studies have shown that the cooling effect of plants has a positive impact on surrounding buildings. The research results showed that if building ventilation behavior is followed correctly, urban greening has an impact on passive cooling both indoors and outdoors. Kubilay [30] used building materials with different heat and moisture transport characteristics to study the degree of evaporative cooling after rainfall of different intensity. The results showed that increasing rainfall intensity extends the effective period of evaporative cooling, but does not change the decrease in maximum surface temperature. The improvement of thermal comfort of the street canyon depends on the combination of many factors, such as moisture permeability, moisture, and thermal diffusivity of materials. Allegrini [31] used building energy simulation to analyze the influence of neighboring buildings on heat flow and its influence on the demand for cooling and heating of the building space. Allegrini [32] compared the space cooling requirements of independent buildings with those of buildings with urban street canyon configurations. The radiation model of solar radiation and long-wave radiation was used to determine the radiation exchange between buildings. The results showed that neighboring buildings had a greater impact on space cooling. This effect depended to a large extent on the control of shading equipment, and this strategy should be combined with building energy management. Vallati [33] used building energy simulation (BES) to analyze the influence of multiple short-wave and long-wave mutual reflection exchanges between neighboring buildings and evaluated their influence on the heat flux of street canyon buildings. The results showed that these radiation exchanges changed the microclimate of the canyon, thereby affecting the space cooling and heating needs of the building. Valliti [34] analyzed the influence of neighboring buildings on heat flow and quantified the mutual influence of buildings on space cooling and heating demand, proving the importance of considering urban microclimate conditions to predict building energy demand.

The purpose of reducing the energy consumption of passive buildings is to make the interior as comfortable or as close to comfortable as possible, from which a variety of passive energy-saving renovation methods are derived. There are many types of reconstruction for buildings, and the emphasis varies according to the climatic conditions in the region. For example, in hot regions, the focus of renovation is on how to effectively reduce the indoor temperature of buildings to meet the requirements of comfortable living [35]. In cold areas, the main consideration is to reduce indoor heat loss as much as possible and enhance the thermal insulation performance of buildings [12]. In areas with high air humidity, the focus is on how to effectively maintain smooth indoor ventilation, thereby reducing the humidity inside the building [36]. Regardless of the purpose, as long as there is no active energy supply, making full use of natural conditions to reach or approach the comfort standard will be accompanied by reduced energy consumption. Passive cooling technology mainly includes three aspects: heat protection, heat modulation, and heat dissipation [37].

The main methods of heat protection include reducing the area of solar radiation, increasing the refractive index of light on the roof, and using plants for shading [38,39]. Its purpose is to ease the speed of heat exchange between indoor and outdoor in summer. Taleb [40] proposed an optimization method for studying energy-saving building forms that can minimize the amount of sunlight while preserving the total building area required. In addition, a software system was constructed and optimized on the back end, and a user interface was provided to test different design parameters and visualize the generated building form. The results showed that the optimization tool could reduce sunlight by up to $48 \%$ while still meeting different site and building criteria. In addition, new wall 
materials or wall thickness adjustments can be used to inhibit the building's ability to absorb solar thermal radiation [41,42].

$\mathrm{Xu}$ [43] studied the latent heat utilization of phase-change materials (PCMs) and proposed the concepts of relative activation depth and activation time rate for the first time. The PCM parameters are optimized by calculating the relative activation depth and activation time rate. The application background is matched to not only achieve building energy conservation but also make better use of latent heat. Khoukhi [44] analyzed the influence of thermal insulation materials with different thermal conductivity on the thermal performance of buildings in an extremely hot climate, and interpreted the impact of the transient thermal conductivity of thermal insulation layers embedded in typical residential buildings on the cooling effect and energy performance. Some scholars have tried to use plants flexibly to shade buildings or absorb heat through transpiration [45]. Hoelscher [46] proposed that exterior wall greening could reduce the thermal stress of the city through shading, transpiration cooling, and heat insulation. The surface temperature of a green exterior wall is $15.5^{\circ} \mathrm{C}$ lower than that of a bare wall, while the surface temperature of the interior wall is as high as $17^{\circ} \mathrm{C}$. The cooling effect depends mainly on the shading, while the lower value is due to transpiration.

Heat modulation involves changing the cooling mode by adjusting the structure of the building itself or finding new ways to change or release the stored heat. Berry [47] provided design parameters related to solar chimneys, and calculated and analyzed indoor air temperature, heating and cooling loads, thermal comfort conditions, energy consumption, energy savings, and the amount of carbon dioxide emission reduction. Zhou [48], in order to explore the operating characteristics of a Ground source heat pump (GSHP) system, used a data acquisition system to monitor it. After that, the measured data were analyzed, including the inlet and outlet water temperature, energy consumption, energy efficiency ratio (EER), coefficient of performance (COP), and ground temperature changes, assuming that the domestic hot water (DHW) system would operate in the next few years. Simulations showed that the operation of the DHW system can effectively reduce the ground temperature and improve system performance. Moosavi [49] focused on the heat and ventilation performance of a newly designed solar chimney, as well as the windshield and water spray system used in two-story office buildings in warm and arid climates. After scaling down the model, a CFD simulation was used to analyze the experimental conditions, which were used to evaluate the cooling and ventilation potential of solar chimneys with and without wind traps. McCartney [50] combined natural ventilation with an unconventional atomization system, and the results showed that a natural ventilation augmented cooling (NVAC) greenhouse could provide a wind speed of $0.38 \mathrm{~m} / \mathrm{s}$ to improve the air circulation in the greenhouse without using a fan. By using the NVAC design, the average turbulence intensity of the air in the greenhouse was increased to $0.32 \mathrm{~m} / \mathrm{s}$, while it was $0.19 \mathrm{~m} / \mathrm{s}$ under natural ventilation conditions. Guo [51] proposed that by increasing roof sunlight reflectance and night ventilation, the cooling load of buildings could be reduced. The simulation showed that compared with a black roof without night ventilation, the cooling energy consumption of the year was reduced by $27 \%$ by combining a cool roof with night ventilation. Compared with a cool roof that did not use night ventilation, the annual cooling energy consumption was reduced by $13 \%$.

Heat dissipation mainly involves transferring the excess heat generated by the building to a suitable radiator. To deal with the excess heat, two factors are mainly considered: the availability of the radiator and the heat conduction efficiency between the radiator and the air, which is the coupling between the two. The surrounding environment can be used as a natural radiator for the building. The type of gas flow and the manner of heat transfer are the keys to determining the heat dissipation efficiency. Zuazua-Ros [52] proposed a third method for heat dissipation in large office buildings: using a hybrid cooling system, or using part of dry heat dissipation panels, or completely replacing the cooling tower. Lule [53], in order to enhance the air exchange of buildings under natural ventilation conditions, used linear heat sources to cover the entire vertical area of the air inlet to study heat dissipation. A constant heat source was used for steady-state and transient experiments, and the heat source was turned off for a period of time during the ventilation process. Infrared thermal imaging was 
used to obtain the two-dimensional temperature distribution around the vent and predict the volume concentration of the fresh air supply through the fully mixed temperature area. Sánchez [54] designed a new system that can utilize solar and wind energy to accelerate the heat dissipation of air-conditioners. The new system is a combination of cooling towers and solar chimneys that increase air flow without using power. Chen [55] used entransy theory to improve the heat transfer process of the central cooling water system of a building and improve the energy utilization efficiency, taking two kinds of simple central cold water systems as an example to put forward an application of the optimization principle.

\subsection{Scientific Originality}

It can be seen from previous studies on the passive cooling of buildings that there are three main cooling measures in summer: introduce cold air from the outside of the building into the space (heat modulation) [56], avoid direct contact between high-temperature outdoor air and indoor air (heat protection) [57], and remove the high-temperature indoor air to the outside of the building (heat dissipation) [58]. The main use of heat modulation is in artificial water circulation, with solar chimneys and atomizers combined with natural ventilation to cool down. When the artificial water circulation system and atomizer cool down, a certain amount of energy consumption is still required to power these processes. It cannot be called a completely passive system; the comparison between the energy consumed and cooling load reduction requires further demonstration. Although a solar chimney can effectively increase indoor ventilation efficiency, it is not obvious for the indoor cooling effect. The use of phase-change materials in heat protection has also had little effect in isolating indoor and outdoor temperatures. The principle of using water for evaporative cooling in heat dissipation is more suitable for desert climates with sufficient sunshine and high water evaporation. Ankang is a city in the subtropical continental monsoon climate and does not meet the climatic conditions of evaporative cooling. The radiator mentioned in [51] is expensive and is more suitable for large public buildings. The cost of renovation needs to be considered for the passive cooling of traditional rural courtyards.

In traditional villages, most of the buildings are leftovers from the Qing Dynasty. The limitations of village planning at that time became the main reason for cold lanes. First of all, the spaces between buildings are too compact, leading to short sunshine time and small areas of solar radiation in the lanes. Second, the overhanging eaves of roofs also act as shields against the sun, also affecting the sunshine in the lanes, leaving them almost without any light during the day. Finally, in a long-term sunless and humid environment, the small space promotes the growth of mosses and ferns, which also take away the surrounding heat during photosynthesis. Under the combined influence of these factors, the temperature in the lanes is lower than the normal outdoor temperature. This kind of lane is very common in villages and is called a cold lane.

In this study, a passive cooling and ventilation system is proposed to lower the indoor temperature and improve the ventilation efficiency of buildings by introducing cold air from cold lanes. This system has three characteristics: heat modulation, heat protection, and heat dissipation. Heat modulation can introduce air from cold lanes to adjust the room temperature; heat protection uses the air wall in front of the wall to isolate the outdoor and indoor temperatures, avoiding direct heat exchange at different temperatures; heat dissipation first introduces cold air into the second floor of the building, then uses the stairwell to convert the heat between the first and second floor, and finally uses hot-pressure ventilation to exhaust the heat from the courtyard.

The entire system completely relies on the accumulation and buoyancy effects of the patio for air circulation, while the indoors relies on hot-pressure ventilation to improve air exchange efficiency. Therefore, the system can run without any power supply, and it is a completely passive ventilation and cooling system. This system is suitable for rural areas with subtropical continental monsoon climates and dense building layouts. 


\subsection{Target of This Research}

The purpose of this study was to measure the wind environment of a traditional village in Shaanxi, China, and then use CFD software for a numerical simulation to explore the differences between simulation cases and actual measurements, and to obtain the results by comparison. A reasonable selection of suitable equations can make the simulation results more accurate. The specific purpose is as follows:

- Compare the cooling and ventilation effects of natural ventilation and the new system to estimate the time and efficiency required under cooling and ventilation conditions.

- Calculate the cooling and ventilation efficiency and the time spent in the whole process considering and not considering wall heat radiation.

- Estimate the time suitable for opening the new system throughout the year.

- Estimate the time to effectively reduce the indoor temperature after using the new system.

- Estimate the value in building cooling load throughout the year after using the new system.

- Provide optimization methods for the passive design of traditional houses and guide the transformation of traditional houses and the establishment of new rural houses.

- In this transformation, connect the indoors and cold lanes, and compare and analyze the original buildings to calculate the cooling capacity, ventilation efficiency, and required time.

- Suggest how to reduce the damage from building renovation to architectural characteristics.

- Propose detailed designs and materials to be used in future research based on physical buildings.

\section{Methodology}

\subsection{Investigation Research}

\subsubsection{Location and Climate}

Shuhe, a traditional village $\left(32.9357^{\circ} \mathrm{N}, 109.7037^{\circ} \mathrm{E}\right)$ located in Ankang City, Shaanxi Province, covers an area of about $0.0264 \mathrm{~km}^{2}$ and is the most popular tourist attraction in Ankang. It belongs to the north subtropical continental humid monsoon climate, with a mild climate, abundant rainfall, and a light and long frost-free period.

Because the buildings in this village are mostly leftover from the Qing Dynasty, they are mainly one- and two-story buildings, with the former accounting for $84.2 \%$ of the total. The height of the first floor is $2.8-3 \mathrm{~m}$, and the total height of two-story buildings is $5.6-6 \mathrm{~m}$. The area density $\lambda \mathrm{p}$ is 0.165 (Figure 1a). Many of the buildings have pitched roofs and patios, which are typical of rural areas of the river valley. Vehicles cannot drive inside the village, because the streets are generally narrow and are sidewalks, and the main streets pass through in the east-west direction. The building and paving materials of the streets are local stone materials. The lack of vegetation in the village and the narrow streets lead to high air temperature in the street canyon in summer. In the whole village, the highest temperature in summer is $37^{\circ} \mathrm{C}$, the lowest temperature in winter is $-3{ }^{\circ} \mathrm{C}$, and the average wind speed is $6 \mathrm{~m} / \mathrm{s}$ (Figure $1 \mathrm{~b}-\mathrm{d}$ ). 


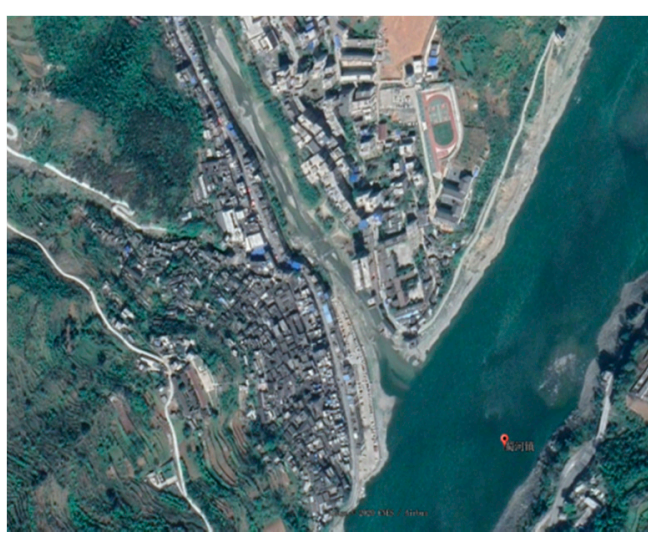

(a)

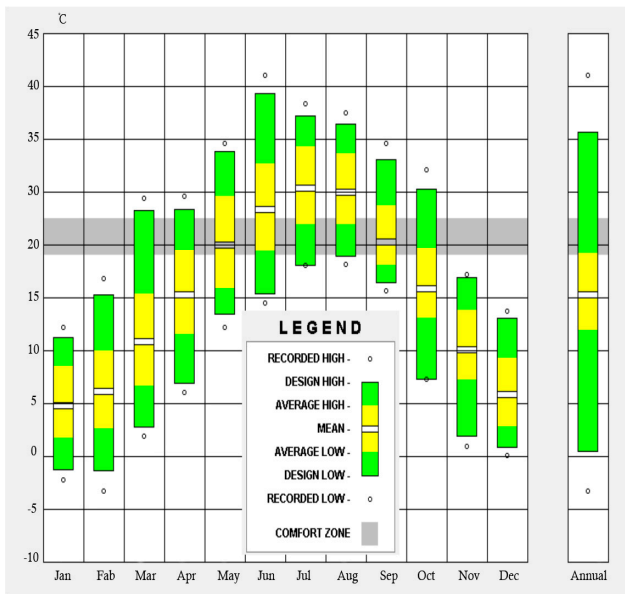

(c)

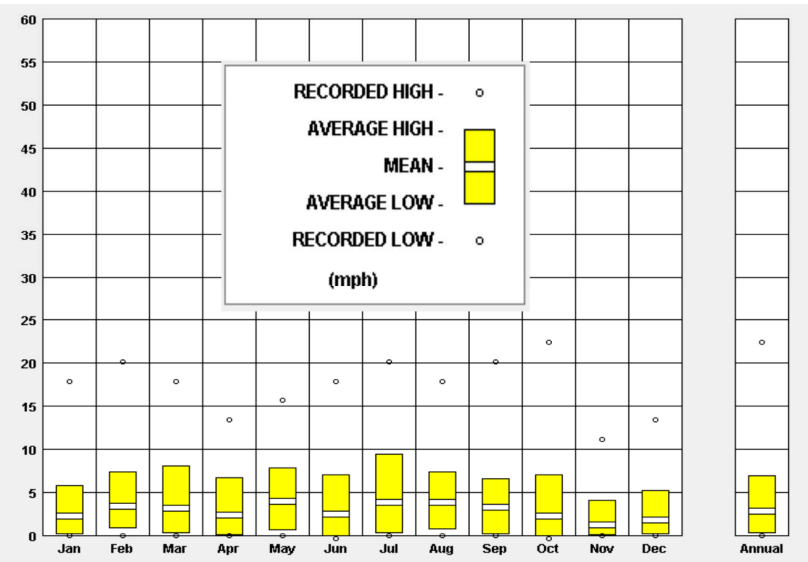

(b)

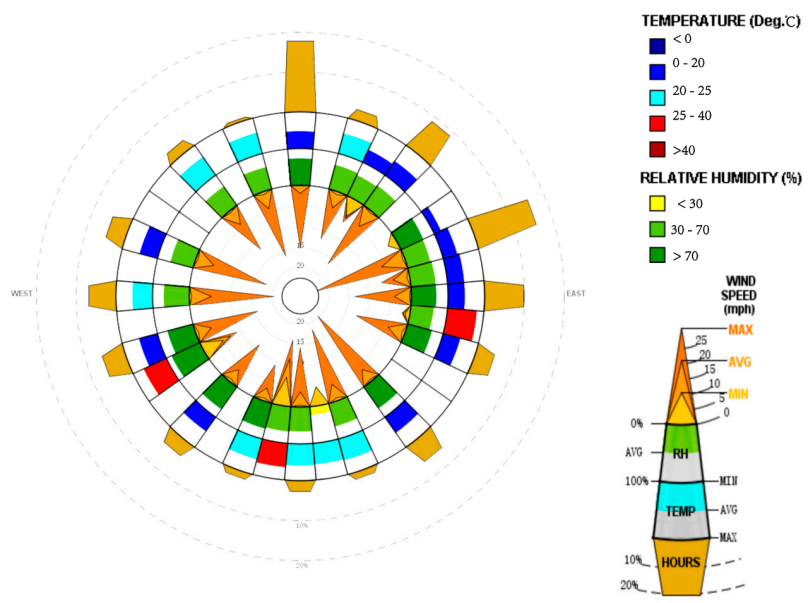

(d)

Figure 1. (a) Village satellite map; (b) annual average wind speed; (c) annual temperature; (d) wind speed, temperature, and humidity distribution throughout the year.

\subsubsection{Study Case}

The research methods adopted for this research were as follows:

- Field research: Collect statistics and summarize the various forms of traditional local houses, and select a number of representative courtyard-style buildings.

- Data measurement: While investigating in the field, select traditional houses related to the research direction for data measurement. The data include indoor and outdoor temperature; outer surface and cold lane temperature; outdoor wind speed; wind speed of building entrance, patio and interior; position and size of doors and windows; angle between the building and the main wind direction within the corresponding time.

- Data summary and organization: The various measured data are processed in a unified manner, and the most representative courtyard-style building is selected as a research case for further study.

- Problem identification: After collating data, it is found that building ventilation and passive cooling performance need to be improved.

- Countermeasures: Consider how to effectively use the air in the cold lane to passively cool the building and improve the indoor ventilation efficiency. 
As shown in Figure 2a, the study case is a closed quadrangle surrounded by four buildings located in the north section of the village. The buildings are divided into two floors; the first floor is $3 \mathrm{~m}$ and the second floor is $2.8 \mathrm{~m}$. The patio space is $9.2 \mathrm{~m}$, and the depth is $22.9 \mathrm{~m}$.

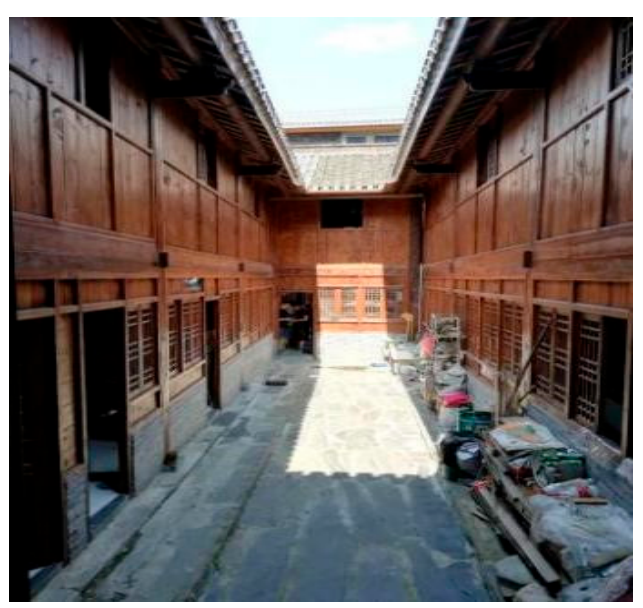

(a)

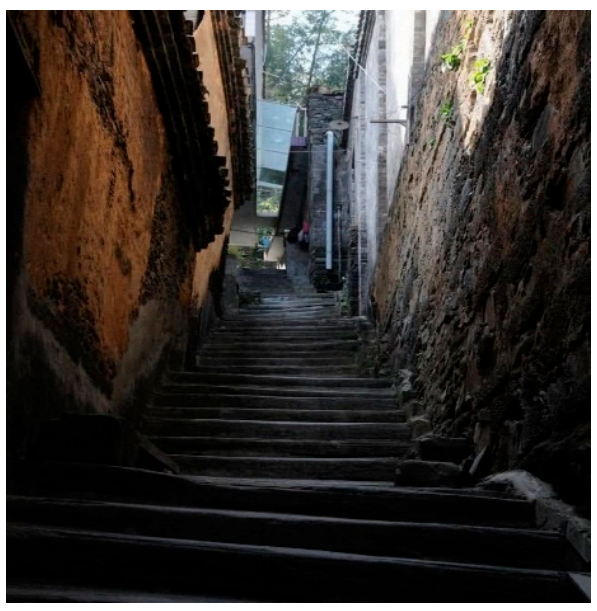

(b)

Figure 2. (a) Base case; (b) cold lane.

The outer envelope structure of the building is blue brick masonry. The building inside the courtyard uses wood as a wall to divide the rooms. All buildings have pitched roofs, which provide favorable conditions for roof drainage, and the overhanging eaves can provide a shading effect, which is used to reduce the thermal radiation inside the courtyard and provide a certain cooling effect. This is a typical traditional Chinese courtyard with a patio at the center. There are many similar buildings in Shuhe village. Most of the buildings in Shuhe village are leftovers from the Qing Dynasty, and the outside street lighting was rarely considered in the design at that time, so the spaces between buildings are very narrow. In addition, traditional buildings were constructed with overhanging eaves, so there is basically no sunlight in the narrow streets throughout the year. Moreover, the annual rainfall in Shuhe is heavy. Therefore, these streets are in a dim and humid state all year round. Coupled with the vertical temperature difference, they can form convection with the hot air in the buildings on both sides to provide ventilation and cooling. This is very conducive to the growth of bryophytes and ferns in a humid environment. Due to the moistening characteristics of bryophytes and the transpiration of ferns, the temperature in streets and lanes is often lower than in the whole village in summer. As shown in Figure $2 b$, streets with this characteristic are called cold lanes.

After analyzing the study cases and cold lanes according to five research methods, we can consider how to use cold lanes to passively cool and ventilate buildings. The main purpose is to be able to introduce the cold air in the cold lane into rooms to undergo thermal conversion with the higher temperature indoor air. Because the temperature in the cold lane is vertically distributed and the air temperature at the bottom is the lowest, it is necessary to connect the bottom of the cold lane with the building interior. However, it is not enough to make holes in the walls of the building. This can only cool down rooms on the first floor near the cold lane. Ventilation and cooling are needed throughout the building. Cold air must enter all rooms. Therefore, a device similar to a container is required. The cold air is collected and then released at a suitable location.

After comprehensive consideration, we designed a cold lane cooling ventilation system to transform the outside of the building into a container to collect the air at the bottom of the cold lane, with the new equipment connected to the second floor of each room. The purpose of this is to make the cold air enter the second-floor rooms first, then go through the stairwell, and the first-floor rooms will also undergo efficient heat exchange. At the same time as heat exchange in the room, due to the 
temperature difference between the cold lane and the patio, hot-pressure ventilation will improve the air flow rate in the room, thereby reducing the frequency of air exchange. The exterior wall of the building will store cold air after the transformation, which is equivalent to an air barrier that prevents direct contact between the external temperature and the wall, reduces the heat transfer rate of the wall, and reduces the effect of the wall heat radiation on the indoor temperature.

\subsubsection{Sunshine Analysis of Cold Lanes}

Figure 3 shows that through the sunshine analysis of the study case, during the whole daytime period, the cold lane has only brief sunshine between 13:00 and 13:40, and the area receiving solar radiation is relatively small-only $1.58 \mathrm{~m}^{2}$. During this period, it was measured that the all-day average temperature in the cold lane was about $5{ }^{\circ} \mathrm{C}$ lower than the normal outdoor temperature, and the temperature variation trend was stable. At 13:00, the temperature rose rapidly, and at other times, it was between 28 and $30^{\circ} \mathrm{C}$ (Figure 4). Figure 5 shows the thermal comfort temperature range based on sunlight analysis.

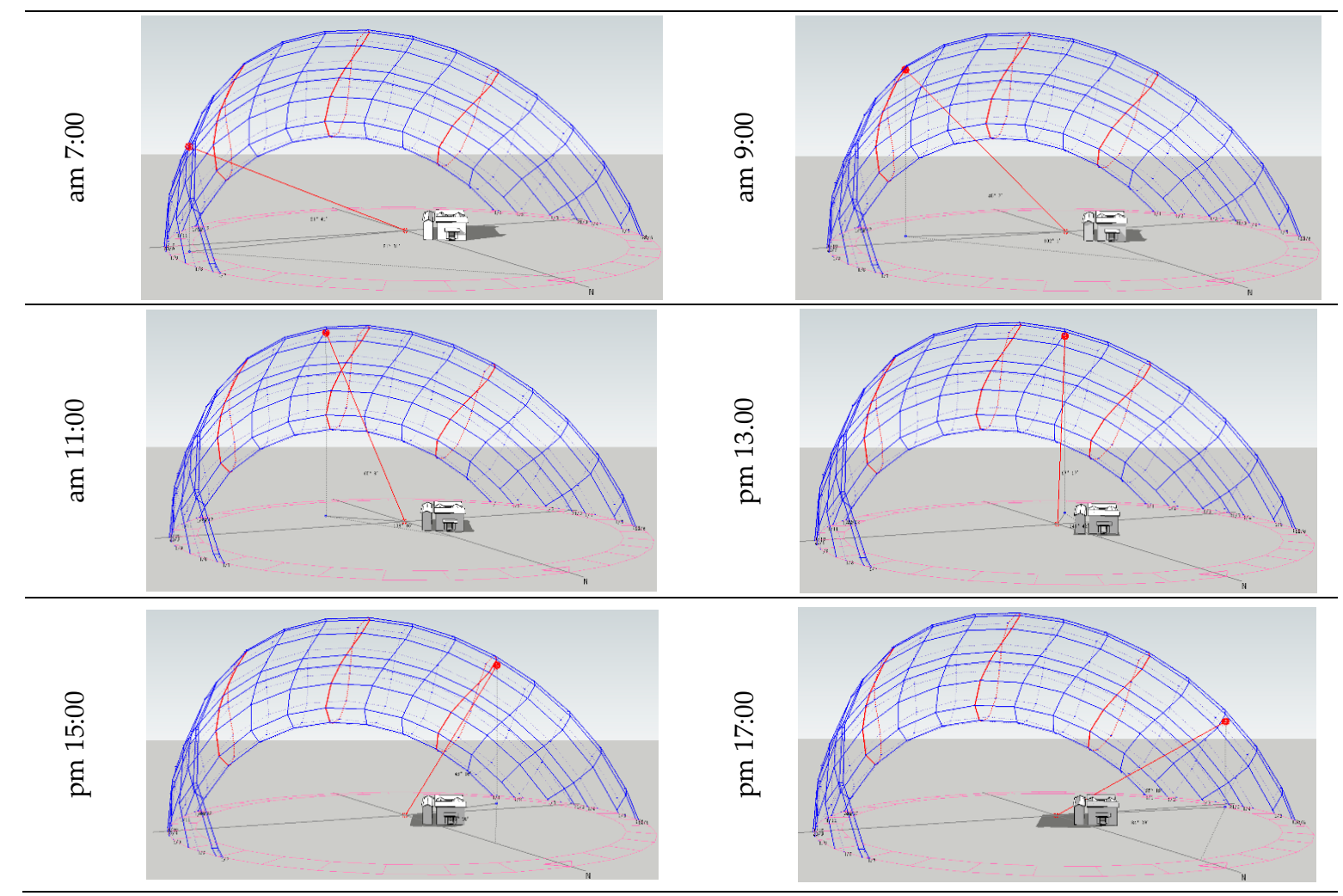

Figure 3. Sunshine analysis of study case.

\subsubsection{Ventilation Analysis of Cold Lane}

Natural ventilation is an economical and practical form of ventilation; it can not only independently satisfy indoor comfort conditions and improve indoor air quality, but also provides effective passive refrigeration and saves energy. As shown in Figure 6, in order to observe the wind speed in streets of different widths, 30 points were selected as the research reference according to the building density, and four areas with different densities were selected for the village. Depending on the building density, the widths of streets and lanes in the four areas vary greatly, and these points are distributed in alleys with inconsistent widths. After the CFD simulation, it can be clearly seen that the air flow velocity in streets varies with the width. At the same natural wind speed, the speed is faster in a wider street and generates more heat. However, in narrow lanes, the air flow is slow, which reduces the efficiency of 
heat exchange between the air in and outside the lane, effectively maintaining the temperature inside. Lanes with the smallest width are cold lanes, which shows that cold lanes have a certain ability to maintain temperature.

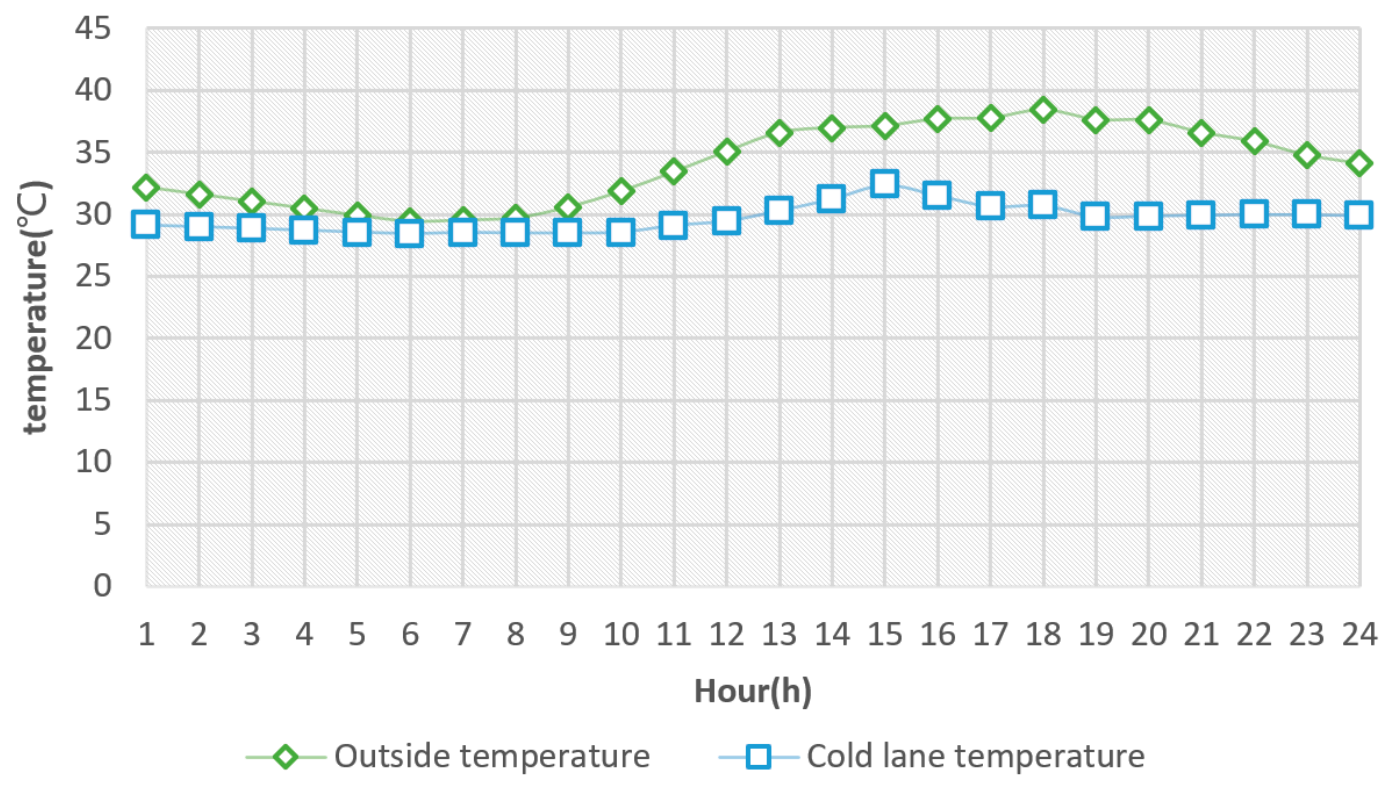

Figure 4. Comparison of outdoor temperature and cold lane temperature.
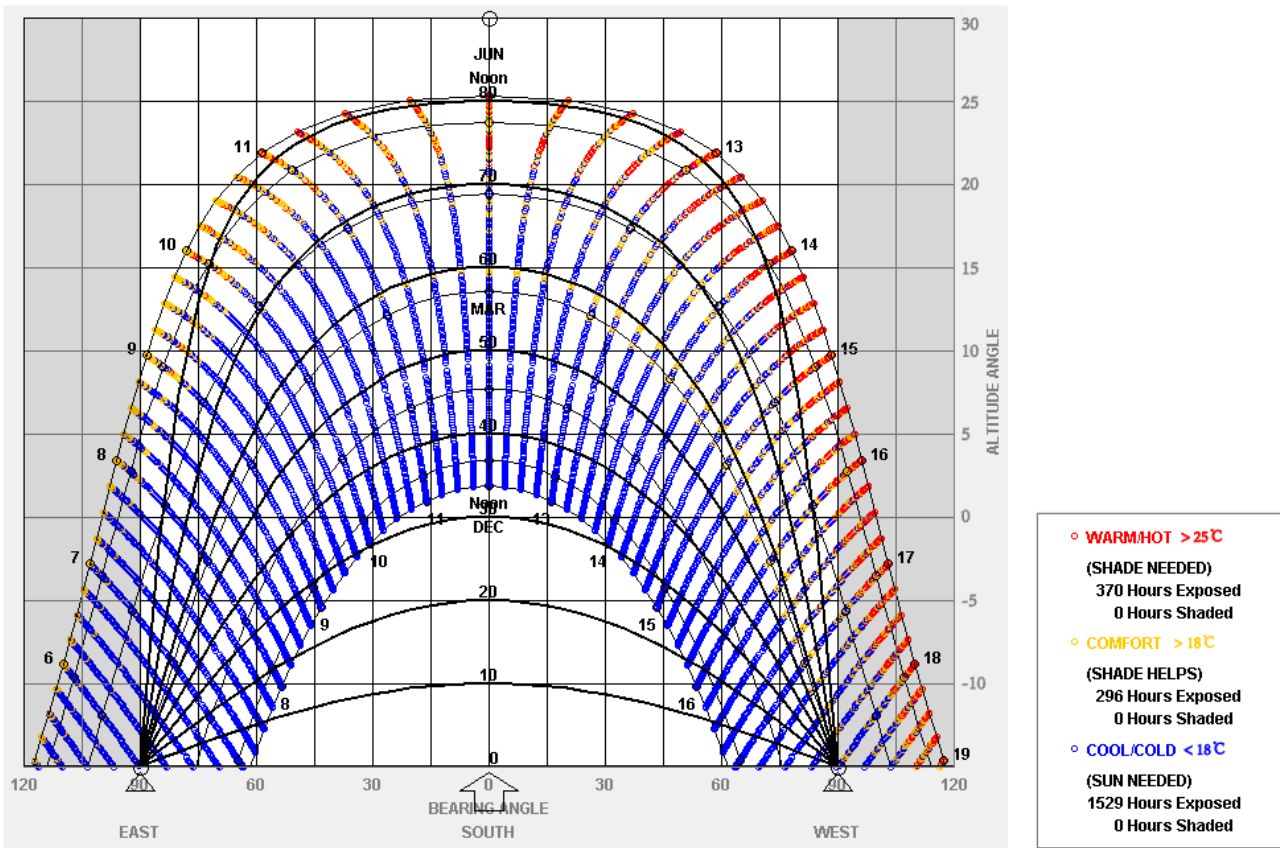

Figure 5. Village sunshine analysis. 


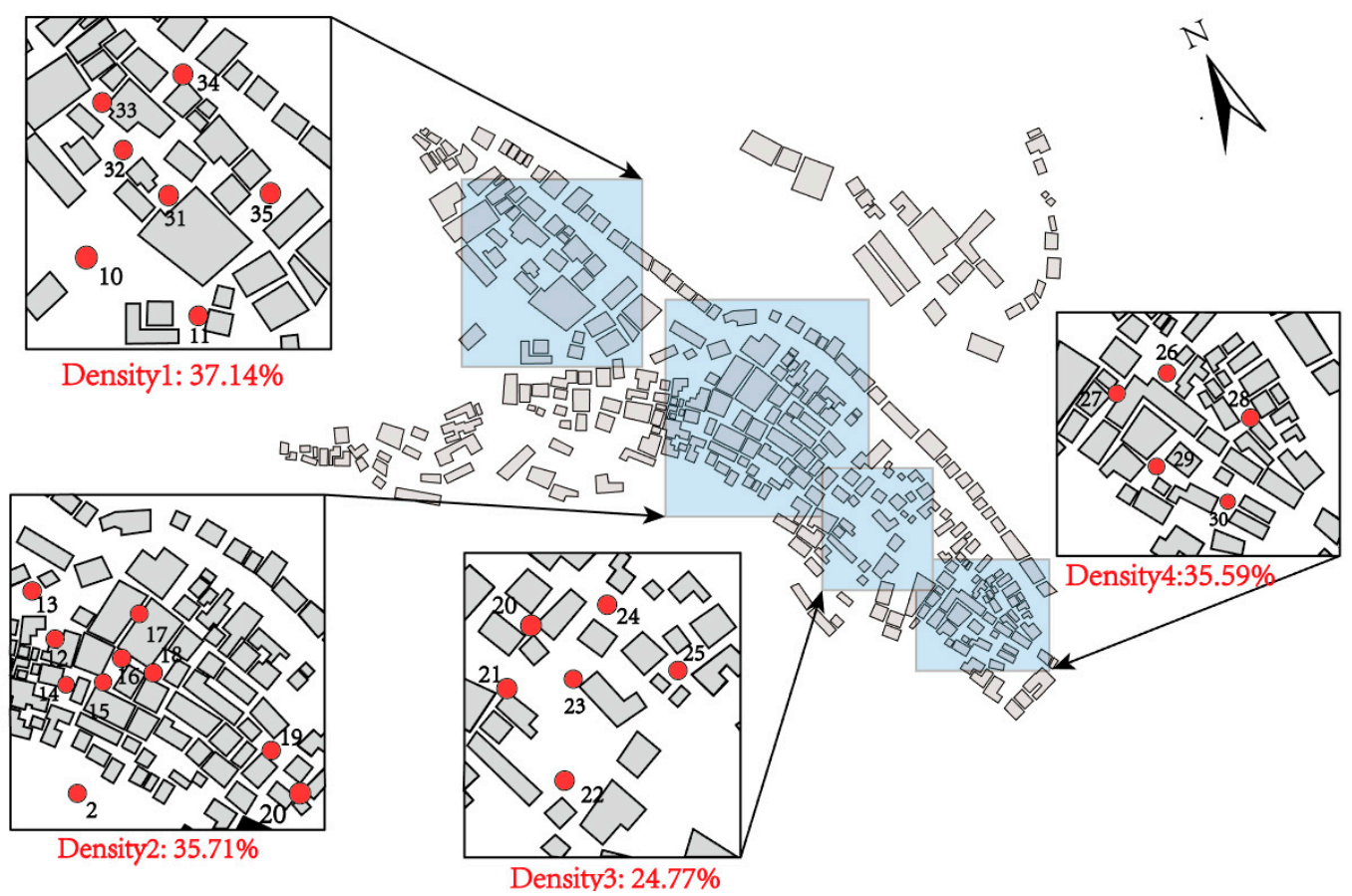

Figure 6. Village with density distribution of test points.

After analysis by Fluent, it can be seen from Figure 7 that the air flow speed in cold lanes is generally faster than that in ordinary streets, and the ventilation performance in the village is positively correlated with building density. Influenced by the difference in air pressure between the entrance and exit of a street, the wind speeds up as the air enters, and the narrower the alley, the faster it moves. The hot air of each building adjacent to the cold air passage will be taken out of the cold lane and the cold air will enter as a supplement to achieve the ventilation effect. The cold lane temperature difference becomes larger with time, resulting in increased thermocompression; it strengthens the air distribution between buildings through hot-pressure ventilation, drives the flow of street air, and takes away the hot air in the street. Combined with the shading effect of the buildings' overhanging eaves, this is an important reason why the air temperature of the courtyard is lower than the ambient temperature. In addition, it can be seen in Figure 6 that due to the obstruction of a large number of buildings, the air velocity entering the village drops significantly, and the wind speed in most cold lanes is only $0.5-1 \mathrm{~m} / \mathrm{s}$. This is negligible for cold lanes. Thus, it can be seen that cold lane ventilation is mainly hot-pressure ventilation. Through the natural ventilation function of cold lanes, cold air is injected into the courtyard, hot air is taken away, and the surrounding outdoor thermal environment is improved.

\subsection{Dealing with Study Case}

\subsubsection{Passive Ventilation Cooling System Setup}

Figure 8a shows the working condition of the original building. The distance between the study case and the adjacent building is $1.5 \mathrm{~m}$, which is the cold lane. The purple area in the figure represents the cold air present in the cold lane. The working conditions of the study case after modification are shown in Figures 9a and 10a: a thin wall $0.24 \mathrm{~m}$ thick was laid on the external wall to re-enclose the external wall of the building, and the distance between it and the original external wall was $0.4 \mathrm{~m}$. This can be regarded as a new ventilation and cooling system for the whole building. Its main function is to introduce the lower temperature air in the cold lane into the crack between the new wall and the original wall through hot-pressure ventilation [59]. First, the air temperature between the two walls is lowered, then the radiant heat exchange between the walls reduces the temperature of the exterior walls, thus reducing the indoor temperature. Second, the air wall formed between the two 
walls constitutes an effective interval that prevents direct contact between the outdoor air and the exterior wall and converts direct heat transfer into indirect heat transfer. The principle is similar to the internal structure of the Thermos cup used in daily life, but the purpose of the Thermos is to isolate the heat in the cup from the lower temperature external environment, while in the case study the purpose is to isolate the higher temperature external environment from the building interior. Finally, the room can be connected with the air wall, and the cold air in the air wall can be directly transported inside to directly cool down the temperature. Next, the cold lane ventilation and cooling system was tested with and without wall heat radiation (WHR).

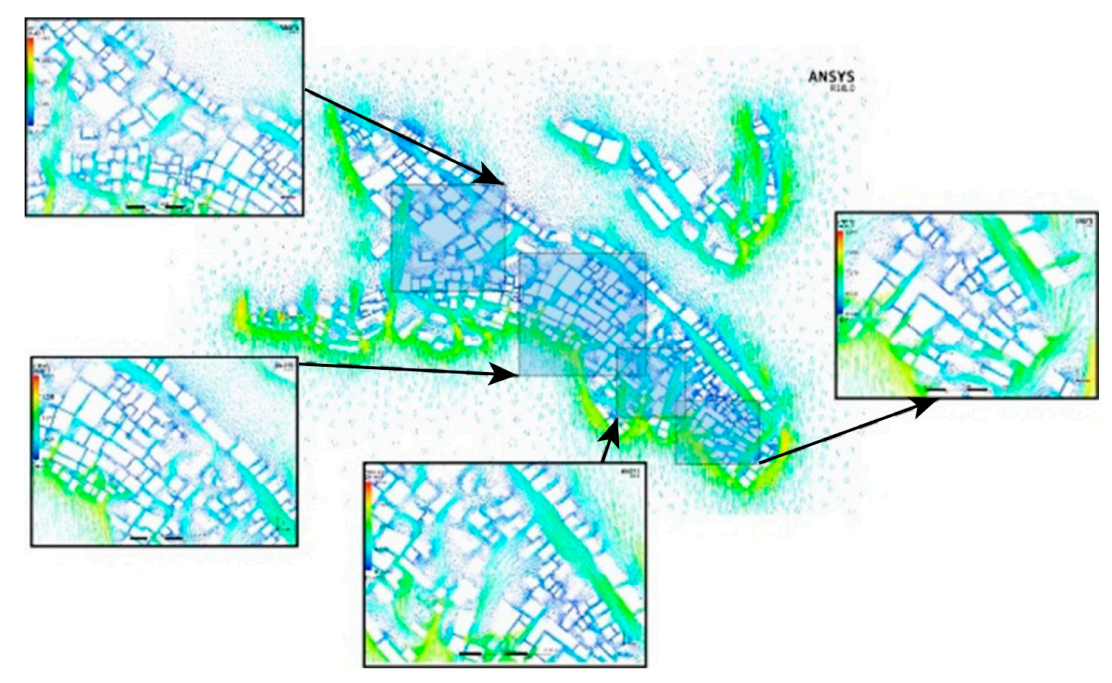

Figure 7. Wind speed with different building density.

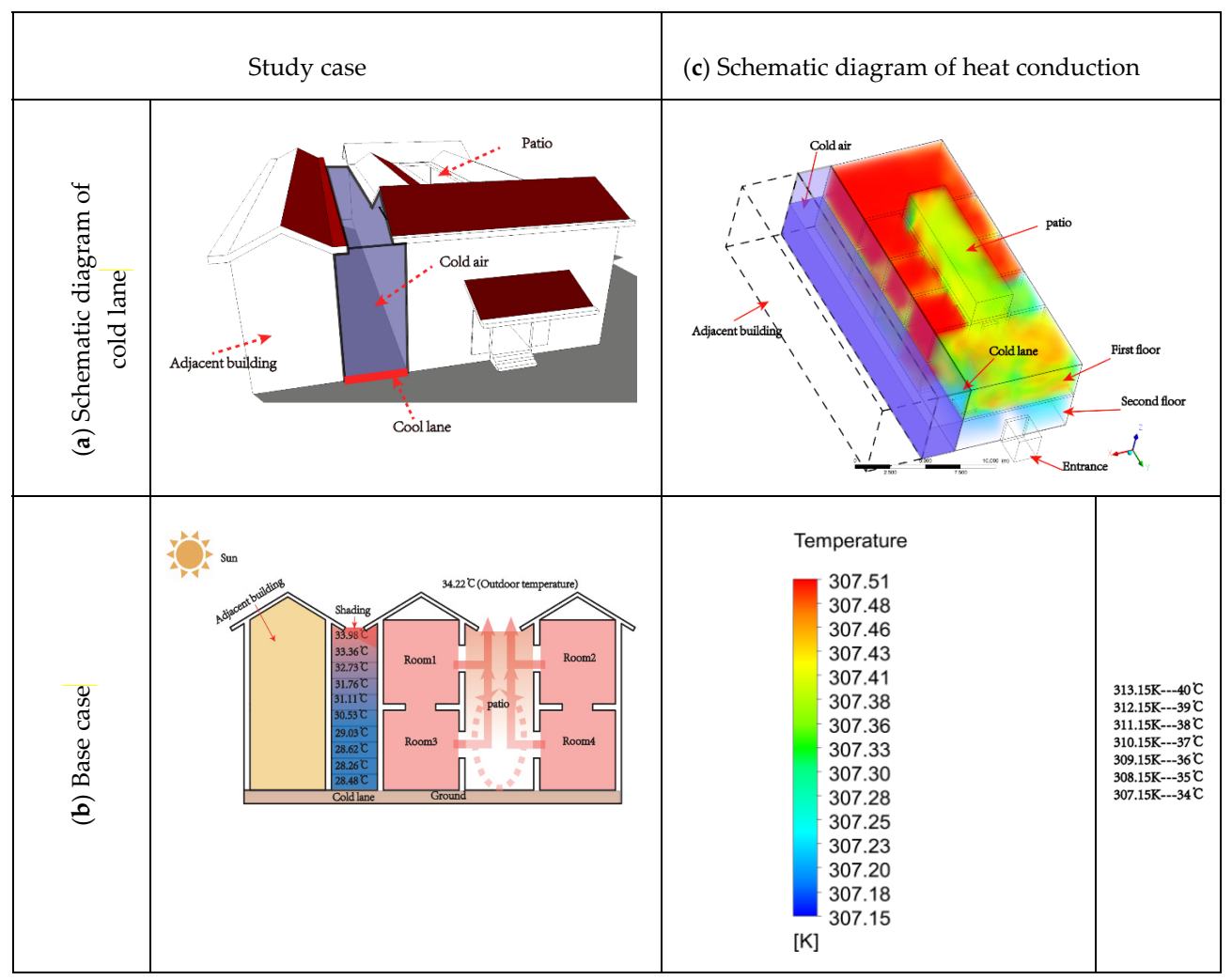

Figure 8. Passive cooling under natural ventilation. (a) Schematic diagram of cold lane); (b) Base case; (c) Schematic diagram of heat conduction. 


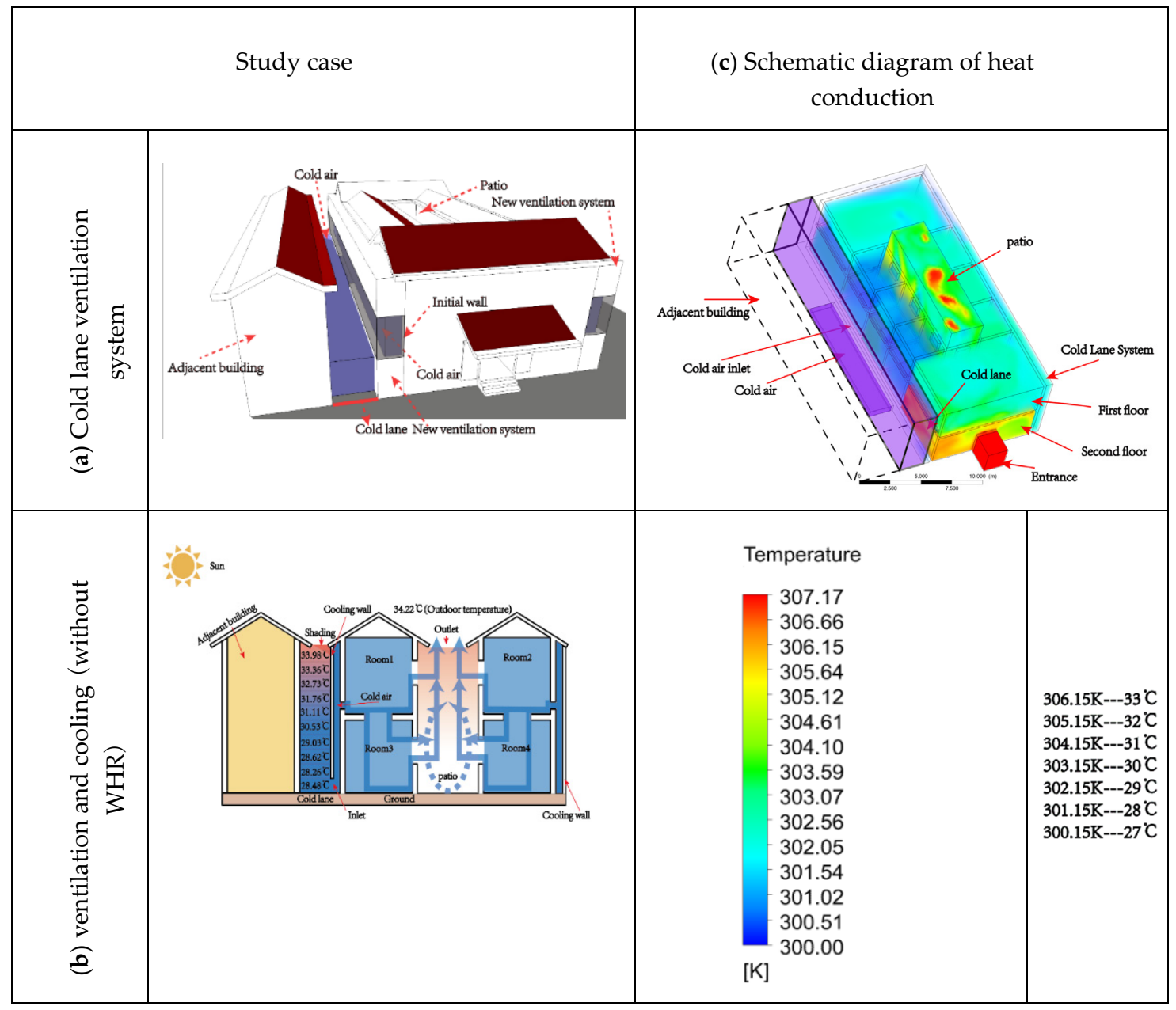

Figure 9. Ventilation and cooling of cold lanes without wall heat radiation (WHR). (a) Cold lane ventilation system; (b) ventilation and cooling (without WHR); (c) Schematic diagram of heat conduction.

\subsubsection{Passive Cooling with Natural Ventilation (Base Case)}

Figure 8 shows the passive cooling of the research case under natural ventilation. The shape and structure of traditional buildings determine the conditions of ventilation and passive cooling. In a traditional Chinese residence, the quadrangular courtyard can be regarded as a ventilation device for the whole building, connected by doors and windows to all rooms. The process of patio ventilation is accompanied by heat exchange. However, because the patio is relatively large for the entire courtyard and has a large contact area with the outside world, there will be basically no cooling. The temperature in the patio is basically the same as the natural temperature outside, but solar radiation can also be controlled by lengthening the roof eaves to reduce the temperature inside the patio, although this approach has little gain. On the other hand, with increased solar radiation intensity in summer, the temperature of the building surface will increase. Because the exterior wall is exposed to direct sunlight for a long time, its surface temperature is higher than the outside air temperature. However, the temperature of the cold lane also has its own transformation rule. As shown in Figure 8b, the temperature in the cold lane mainly changes vertically; while the temperature at the bottom is relatively low, it gradually rises up to the top, where it is roughly equal to the outside temperature. Through actual measurement, the temperature difference between the lowest and highest point of a cold lane is within $5^{\circ} \mathrm{C}$. 


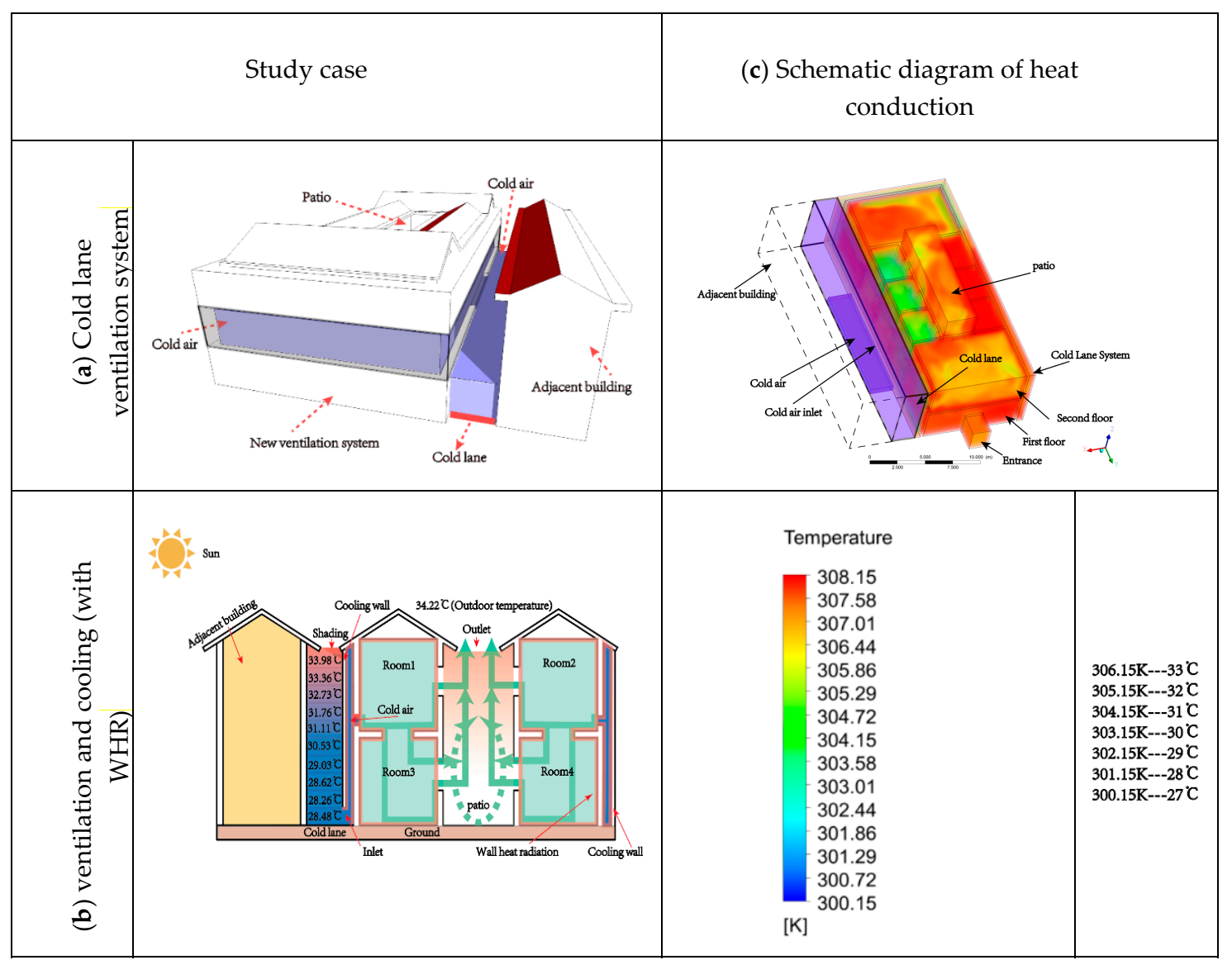

Figure 10. Ventilation and cooling of cold lanes with WHR. (a) Cold lane ventilation system; (b) ventilation and cooling (with WHR); (c) Schematic diagram of heat conduction.

Figure $8 \mathrm{c}$ shows a schematic diagram of heat conduction between rooms and a courtyard in a traditional village under natural ventilation. It can be seen from the figure that the indoor temperature of the first floor is greatly affected by ventilation. As mentioned above, the indoor temperature is higher than the outdoor temperature in the summer without other auxiliary means. When lower temperature outdoor air flows through the patio gate into the room, it circulates on the first floor, so the room temperature near the gate drops faster. When the air flows, it also undergoes heat exchange with the indoor air. Therefore, when the air flows to the room far from the courtyard gate, the air temperature is basically the same as the room temperature, and basically does not rise to any cooling effect. In the second-story interior, this problem is more prominent and common. On the first floor, the air temperature changes obviously over a period of time, while on the second floor, except for the room closest to the gate, the temperature hardly changes at all. However, although the figure shows a large change in room temperature on the first floor, the difference is less than $1{ }^{\circ} \mathrm{C}$.

\subsubsection{Passive Cooling without Wall Heat Radiation}

In the description of passive cooling under natural ventilation, it was mentioned that the room temperature of the first floor changes greatly. The second floor basically does not change, and the temperature difference caused by the outside temperature entering the room is only about $1{ }^{\circ} \mathrm{C}$. Based on this situation, the new ventilation and cooling system installed outside the wall shows its advantages. As mentioned earlier, the new system can solve the problems of isolation from external heat, wall heat conduction, and direct indoor cooling. Most important is to bring the lowest temperature 
air at the bottom of the cold lane into the room for heat exchange through hot-pressure ventilation, thus reducing the indoor temperature.

Therefore, in this study, all the rooms on the second floor were connected with the new system, and the connection mode is shown in Figure 9b. After the cold air enters the second floor rooms, the air in the first and second floors is exchanged by the stairwell to achieve the effect of cooling the whole building at the same time. Figure $9 \mathrm{c}$ shows the effect of introducing cold air from the cold lane into the building interior. After a period of time, the temperature of the first and second floors drops significantly compared to natural ventilation and cooling. The room on the side near the gate changes less because it is ventilated by ordinary outside air, which is similar for the courtyard.

\subsubsection{Passive Cooling with Wall Heat Radiation}

In summer, due to the intense solar radiation, the outer surface temperature of a building is much higher than the outdoor air temperature. Heat absorbed by the surface will first be conducted from the outside to the inside through the internal materials of the wall, and when it reaches the interior wall, it will transfer the heat to the indoor air in the form of heat radiation, causing the indoor temperature to rise. This is another decisive factor that greatly affects indoor temperature besides ventilation. The temperature transmission speed is determined by the material of the wall and the color of the building surface. However, in previous studies on the passive cooling of buildings, most researchers ignored this important factor. The wall heat radiation or lack of to a large extent determines the accuracy of software simulations compared with real life and the availability of simulation results.

Figure $9 \mathrm{c}$ shows the simulated working conditions of the building without considering the thermal radiation of the wall. It can be seen that in a period of time, the cooling efficiency of the new ventilation system is very efficient, and some rooms can be quickly cooled to the same temperature as the cold lane. If this state continues, under ideal circumstances, except for the room near the courtyard door, the rooms will eventually reach the same temperature as the lowest temperature in the cold lane. However, if we consider wall heat radiation, as shown in Figure 10c, after the cold air from the cold lane enters the room, it has to exchange heat not only with the indoor air, but also with the radiant temperature of the wall. The heat radiation from the wall basically maintains a constant temperature state, equivalent to an indoor "heater"; when the cold air reaches an equilibrium point after the heat exchange, the indoor temperature will not change significantly afterwards. Similarly, without considering heat radiation over time and the temperature brought by the comprehensive natural ventilation, the indoor temperature will also reach an equilibrium point and no more changes will occur. Based on the cold lane ventilation system, in the cases with and without WHR, there was improvement of the ventilation effect of the whole building, the temperature and time reaching the equilibrium point, and the value of reduced cooling load in the building.

\subsection{Simulation Scheme}

In order to estimate the cooling load reduction in the new system with and without WHR, the time it takes to cool the room, and the final temperature after cooling, some simulation tools are needed to present the results. To simulate the indoor and outdoor ventilation, temperature, and heat conversion of buildings, the main tool used is the large eddy simulation and radiation algorithms in Fluent. The large eddy simulation algorithm can accurately calculate the time it takes for natural ventilation and heat conversion of the air, and present the ventilation status. The radiation algorithm is used to calculate the heat radiation of the wall and the details of the heat exchange process between the wall and the indoor air. The simulation tool for calculating building cooling load includes Grasshopper, Ladybug, and Honeybee. Rhinoceros is used for modeling, and then Ladybug is used to import weather data and Honeybee to set the building-related thermal parameters, and finally connect to Energy Plus for simulation calculations related to energy consumption.

The simulation in this study was mainly divided into four stages. The first stage is to simulate natural ventilation. After modeling based on the measured data of the building, the model is set 
according to local summer climatic conditions, including outdoor air temperature and dominant wind direction. According to the actual situation of the building, the wall, roof, doors and windows, ground, and other structural materials are set to simulate a set of natural ventilation data as a benchmark for comparison. The second stage is to set up the cold lane ventilation and cooling system, simulate with and without WHR, and collect and process the data of overall ventilation effect, temperature, and time. In the third stage, the cooling load reduced with and without WHR based on the new system is calculated, and the two conditions are compared and analyzed. Finally, the overall ventilation efficiency of the entire building, the temperature at the equilibrium point, the time consumed, and the total cooling load reduced throughout the year after adding the cold lane ventilation and cooling system are calculated. Table 1 contains the basic information of the study case, including the area, quantity, and location of the building, the climate zone, and the total area of each room. According to the China Affordable Housing Design Code [60], the minimum living area is $4 \mathrm{~m}^{2} /$ person, or 0.25 people $/ \mathrm{m}^{2}$. However, considering that the rural population base is relatively small and the per capita building area is relatively large, there are only three households in the study case. If three people are evenly allocated to 16 rooms, the population density will be too small. Therefore, setting the population density parameter to 1.1 persons will help improve the accuracy of the simulated data. Table 2 introduces the detailed construction method of the building and the materials used; Table 3 lists the density of building materials, thermal conductivity, heat storage coefficient, and specific heat.

Table 1. Basic information of the study case.

\begin{tabular}{cl}
\hline Courtyard Parameter & \multicolumn{1}{c}{ Detailed Description } \\
\hline Building location & Shuhe, Ankang, Shaanxi Province, China $\left(32.9357^{\circ} \mathrm{N}, 109.7037^{\circ} \mathrm{E}\right)$ \\
Climate zone & Hot summer and cold winter \\
Simulation time & All times throughout the year when the temperature exceeds $28^{\circ} \mathrm{C}$ \\
Room information & $5.6 \mathrm{~m}(\mathrm{w}) \times 9.22 \mathrm{~m}(\mathrm{l}) \times 3 \mathrm{~m}(\mathrm{~h}) \times 4 ; 3 \mathrm{~m}(\mathrm{w}) \times 4 \mathrm{~m}(\mathrm{l}) \times 3 \mathrm{~m}(\mathrm{~h}) \times 12$ \\
Total surface area & $349.04 \mathrm{~m}^{2}$ \\
Population density & 1.1 people per room \\
\hline
\end{tabular}

Table 2. Detailed structure of the study case.

\begin{tabular}{cl}
\hline Building Material Parameters & \multicolumn{1}{c}{ Details } \\
\hline \multirow{2}{*}{ Exterior wall } & Cement mortar $(15 \mathrm{~mm})+$ Masonry structure $(240 \mathrm{~mm})$ \\
& + Cement mortar $(15 \mathrm{~mm})+$ White lime $(2 \mathrm{~mm})$ \\
& Ceramic tile $(10 \mathrm{~mm})+$ Cement mortar $(10 \mathrm{~mm})+$ \\
& Reinforced concrete $(100 \mathrm{~mm})$ \\
& White lime $(2 \mathrm{~mm})+$ Cement mortar $(15 \mathrm{~mm})+$ Masonry structure \\
& $(120 \mathrm{~mm})+$ Cement mortar $(15 \mathrm{~mm})+$ White lime $(2 \mathrm{~mm})$ \\
& Thickness $(6 \mathrm{~mm}) ;$ solar transmittance at normal incidence: $0.775 ;$ \\
& front side solar reflectance at normal incidence: $0.071 ;$ back side \\
& solar reflectance at normal incidence: $0.071 ;$ visible transmittance \\
& at normal incidence: $0.881 ;$ front side visible reflectance at normal \\
& incidence: $0.08 ;$ back visible reflectance at normal incidence: $0.08 ;$ \\
& front side infrared hemispherical emissivity: $0.84 ;$ back side \\
& infrared hemispherical emissivity: $0.84 ;$ conductivity: W/m $\mathrm{k}$ \\
& Bluestone tile $(6 \mathrm{~mm})+$ Waterproof mortar $(6 \mathrm{~mm})+$ Ceramic tile \\
& $(10 \mathrm{~mm})+$ Cement mortar $(15 \mathrm{~mm})+$ White lime $(2 \mathrm{~mm})$ \\
&
\end{tabular}


Table 3. Related parameters of building materials.

\begin{tabular}{|c|c|c|c|c|}
\hline Material & $\begin{array}{c}\text { Density }(\rho) \\
\mathrm{kg} / \mathrm{m}^{3}\end{array}$ & $\begin{array}{c}\text { Thermal } \\
\text { Conductivity }(\lambda) \\
\mathrm{W} / \mathrm{m} \cdot \mathrm{K}\end{array}$ & $\begin{array}{c}\text { Thermal Storage } \\
\text { Coefficient (S) } \\
W /\left(\mathrm{m}^{2} \cdot \mathrm{K}\right)\end{array}$ & $\begin{array}{c}\text { Specific Heat } \\
\text { Capacity (C) } \\
\text { kj/(kg.K) }\end{array}$ \\
\hline Cement mortar & 1800 & 0.93 & 11.37 & 1.05 \\
\hline Masonry structure & 1700 & 0.76 & 9.96 & 1.05 \\
\hline White lime & 1600 & 0.81 & 10.07 & 1.05 \\
\hline $\begin{array}{l}\text { Reinforced } \\
\text { concrete }\end{array}$ & 2300 & 1.51 & 15.36 & 0.92 \\
\hline Bluestone tile & 2000 & 1.16 & 12.56 & 0.92 \\
\hline Waterproof mortar & 600 & 0.17 & 3.33 & 1.47 \\
\hline
\end{tabular}

\section{Results and Discussion}

\subsection{Comparison of Natural Cooling with and without WHR}

\subsubsection{Cooling Time and Final Equilibrium Temperature}

In order to observe the cooling efficiency of cold lane ventilation more intuitively, natural ventilation was used as a benchmark for comparison. As shown in Figure 11, in the first four minutes (Figure 11a,b), the cold lane ventilation system already showed its advantages. The cold air from the cold lane directly entered the second floor, ran through the entire room, and began to exchange heat with the warmer air inside the room. However, for natural ventilation, the outdoor air at this time just passed through the courtyard door and circulated in the first room, and the temperature was only $1{ }^{\circ} \mathrm{C}$ lower than the indoor air temperature. At $16 \mathrm{~min}$, under the condition of natural ventilation (Figure 11c), the air entering the patio filled the first room and flowed inside the courtyard. In the case where other rooms were not cooled, part of the air with lower temperature returned to the outside through the patio. With the new system (Figure 11d), the cold air from the cold lane circulated on three sides of the room through the system, which brought the cold air into the second floor room on the other side of the patio. At this time, the temperature of most areas in the room close to the cold lane is close to the temperature of the cold lane. The cold air on the second floor continues to spread to the first floor through the stairwell because cold air sinks, and part of it flows to the courtyard through the doors and windows.

After $33 \mathrm{~min}$, under natural cooling (Figure 11e), the outdoor air flow poured into the courtyard through the gate, the temperature in the courtyard dropped slightly, and the cold air at lower height entered the first floor of the building. However, the temperature in almost the whole second floor did not improve. At this time, the temperature was lower on the first floor than the second floor, but higher than in the courtyard. In the cold lane ventilation system (Figure 11f), the temperature of the second floor room near the cold lane reached $28^{\circ} \mathrm{C}$, and the temperature in the first floor room also changed significantly. In the six rooms farther from the cold lane, the temperature on the second floor also dropped from the original 34 to about $32{ }^{\circ} \mathrm{C}$, and the air in the room on the first floor was exchanged with the air in the room on the second floor. The temperature near the ceiling of the room on the first floor was significantly lower than that near the ground.

After $2.22 \mathrm{~h}$ of ventilation, the cold air filled the whole patio in the courtyard, relying on natural ventilation (Figure 11g). Cold air flowed into the room through the patio, reducing the temperature by about $1^{\circ} \mathrm{C}$ in most of the rooms. However, the temperature of the rooms farther from the air inlet did not reach $1{ }^{\circ} \mathrm{C}$ yet. Under the action of the cold lane ventilation system (Figure $11 \mathrm{~h}$ ), the room temperature decreased by 3 to $4{ }^{\circ} \mathrm{C}$ on average, and the second floor room near the gate had a significant temperature drop because it was connected to the cold lane. In contrast, the temperature dropped very slowly in the first layer because it was also affected by the warmer air outside compared with the gate, and the new system connecting the room had a smaller cross-sectional area and slower wind speed. A large amount of air entered the room through the gate in unit time and the speed was also faster, so the cooling effect was not obvious. Finally, it was shown that the building with natural ventilation 
reached the temperature equilibrium point (Figure 11i) within $6.11 \mathrm{~h}$, at about $34^{\circ} \mathrm{C}$, which was about $1{ }^{\circ} \mathrm{C}$ lower than before. However, the building with the cold lane ventilation system reached the temperature equilibrium point (Figure $11 \mathrm{j}$ ) after $2.77 \mathrm{~h}$ or so, and the average temperature was $28.8^{\circ} \mathrm{C}$, which was about $4-5{ }^{\circ} \mathrm{C}$ lower than before. In addition, it was also found in the simulation that the patio temperature was first lowered by natural ventilation cooling, then the cold air was transferred through it to the room for heat transfer, but in real life, it is not easy to reduce the temperature in the patio. In this process, a lot of cold air will be wasted, which will greatly reduce the heat exchange efficiency. However, when the cold lane ventilation system delivers cold air, it can skip the process of heat exchange with the patio and directly deliver cold air to each room, greatly increasing the cooling rate. In terms of heat exchange time, the cooling time of the cold lane ventilation system is only one-third the natural ventilation heat exchange time. As for cooling efficiency, the average cooling efficiency of natural ventilation is $0.16{ }^{\circ} \mathrm{C} / \mathrm{h}$, and that of the cold lane ventilation system is $1.81^{\circ} \mathrm{C} / \mathrm{h}-10.8$ times larger.

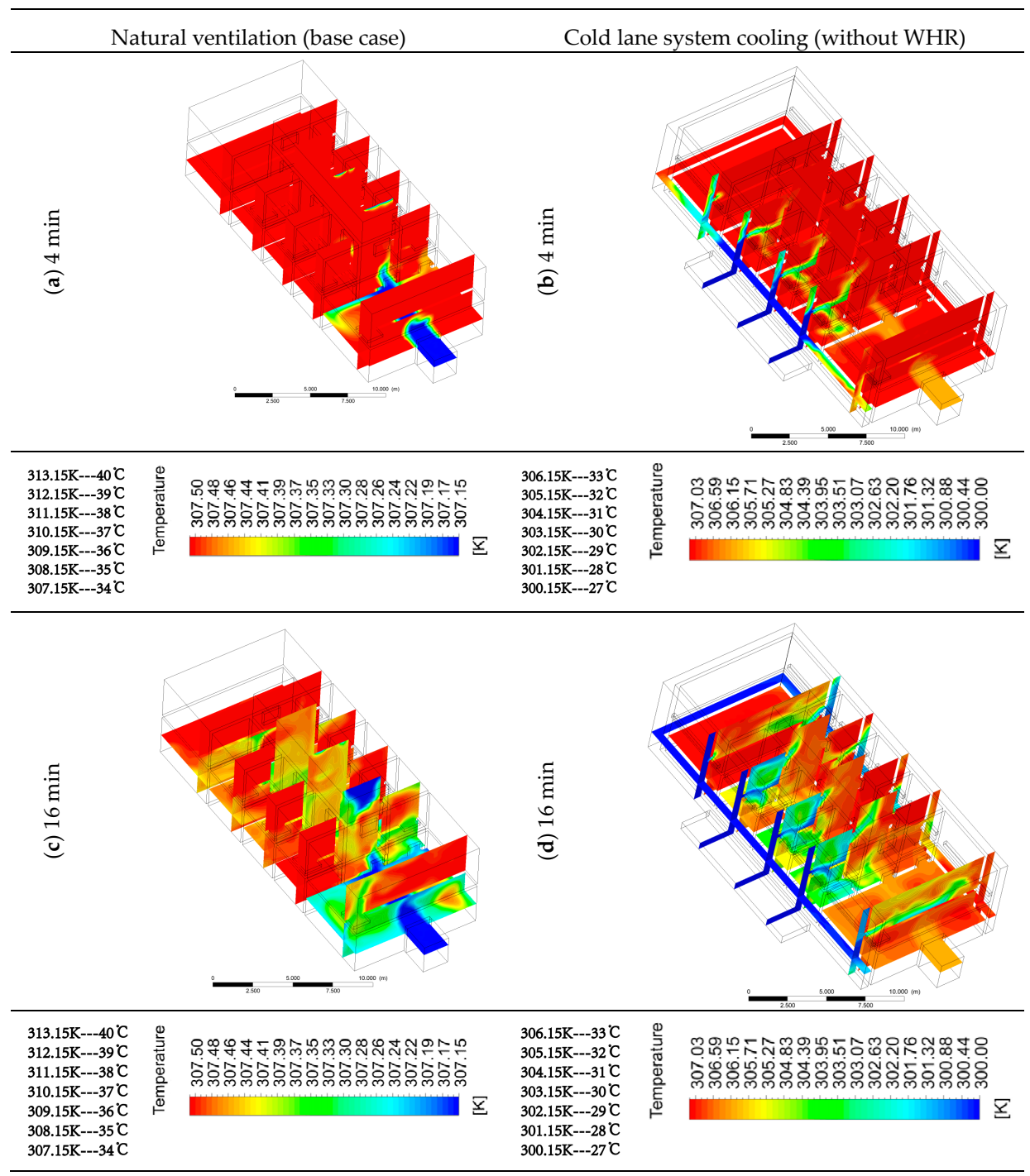

Figure 11. Cont. 

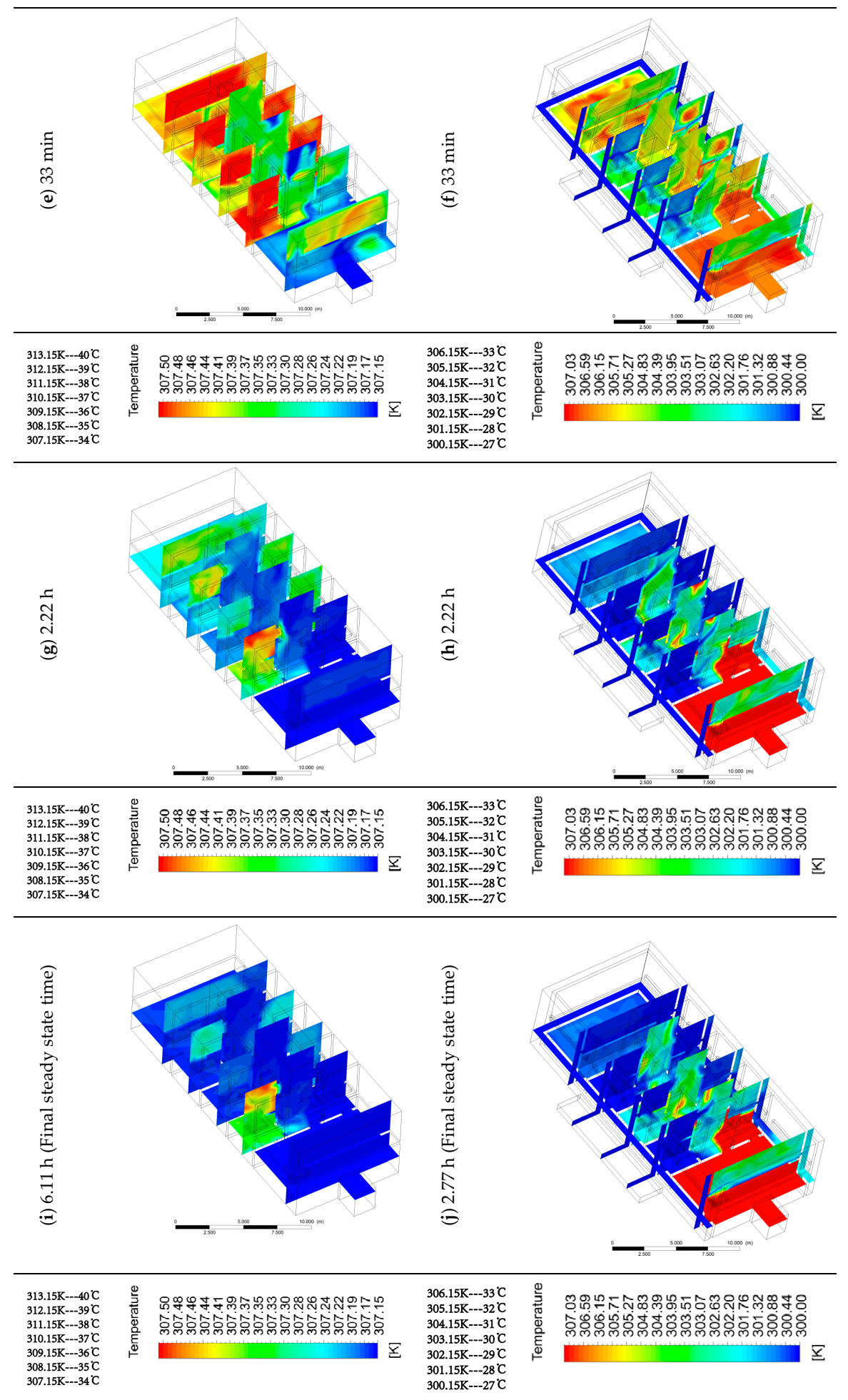

Figure 11. Comparison of cooling time between natural ventilation and new system (without WHR). (a) 4 min of natural ventilation; (b) 4 min of cold lane system cooling (without WHR); (c) 16 min of natural ventilation; (d) 16 min of cold lane system cooling (without WHR); (e) 33 min of natural ventilation; (f) 33 min of cold lane system cooling (without WHR); (g) $2.22 \mathrm{~h}$ of natural ventilation; (h) $2.22 \mathrm{~h}$ of cold lane system cooling (without WHR); (i) 6.11 h (Final steady state time); (j) $2.77 \mathrm{~h}$ (Final steady state time). 


\subsubsection{Cold Lane System Ventilation}

The radiation rate of heat is significantly lower than the flow rate of air. The ventilation effects of natural ventilation with and without WHR are shown in Figure 12. It can be seen that at 4 min there was a significant difference between the two in ventilation. The naturally ventilated courtyard still relied on the patio for ventilation (Figure 12a); the air from the outside entered the courtyard first, and could not enter each room the first time. Furthermore, the flow of air depends on whether there is a pressure difference between the two sides of the flow, influenced by the construction methods of traditional dwellings. The rooms in the courtyard only have windows open on the side close to the patio, the interior does not have a transparent air flow environment, and the indoor natural ventilation has poor ventilation efficiency. Before the time when the temperature reaches the equilibrium point (Figure 12i) in $6.11 \mathrm{~h}$, the ventilation effect in the room is not very obvious; most of the airflow only flows in the patio, and little flows into the room. Only the airflow near the gate flows at a faster rate; for the cold ventilation system, the ventilation effect is more ideal. Within $2.77 \mathrm{~h}$ (Figure 12j), when the temperature reaches the equilibrium point, the airflow introduced from the cold lane first passes through the room to the patio, and then to other rooms. The new system and the patio are combined for ventilation, making the airflow in the entire building, both the patio and indoors, more active, so that the indoor ventilation efficiency is greatly improved. The ventilation time in the building was shortened from 33 to $4 \mathrm{~min}$.

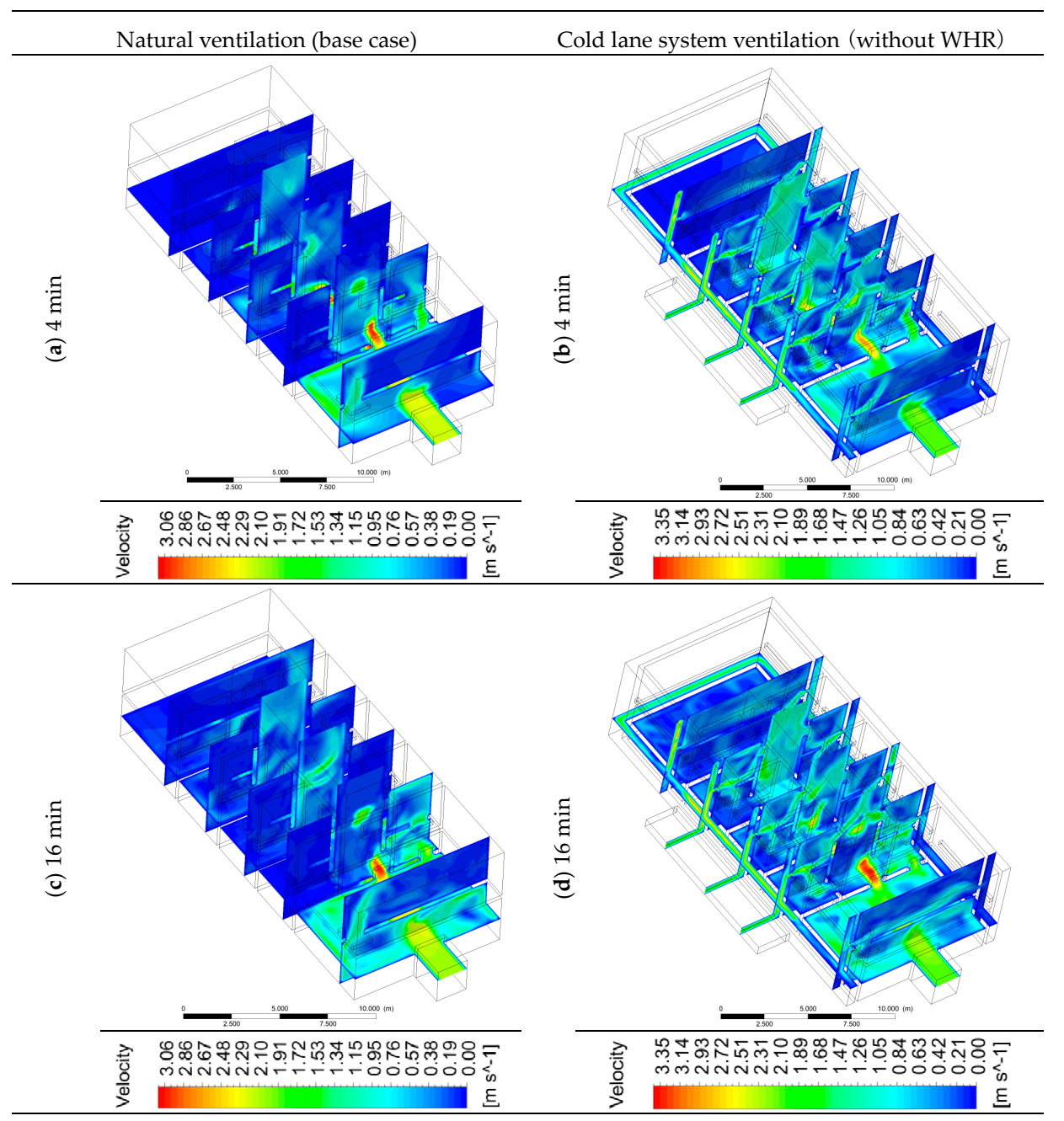

Figure 12. Cont. 

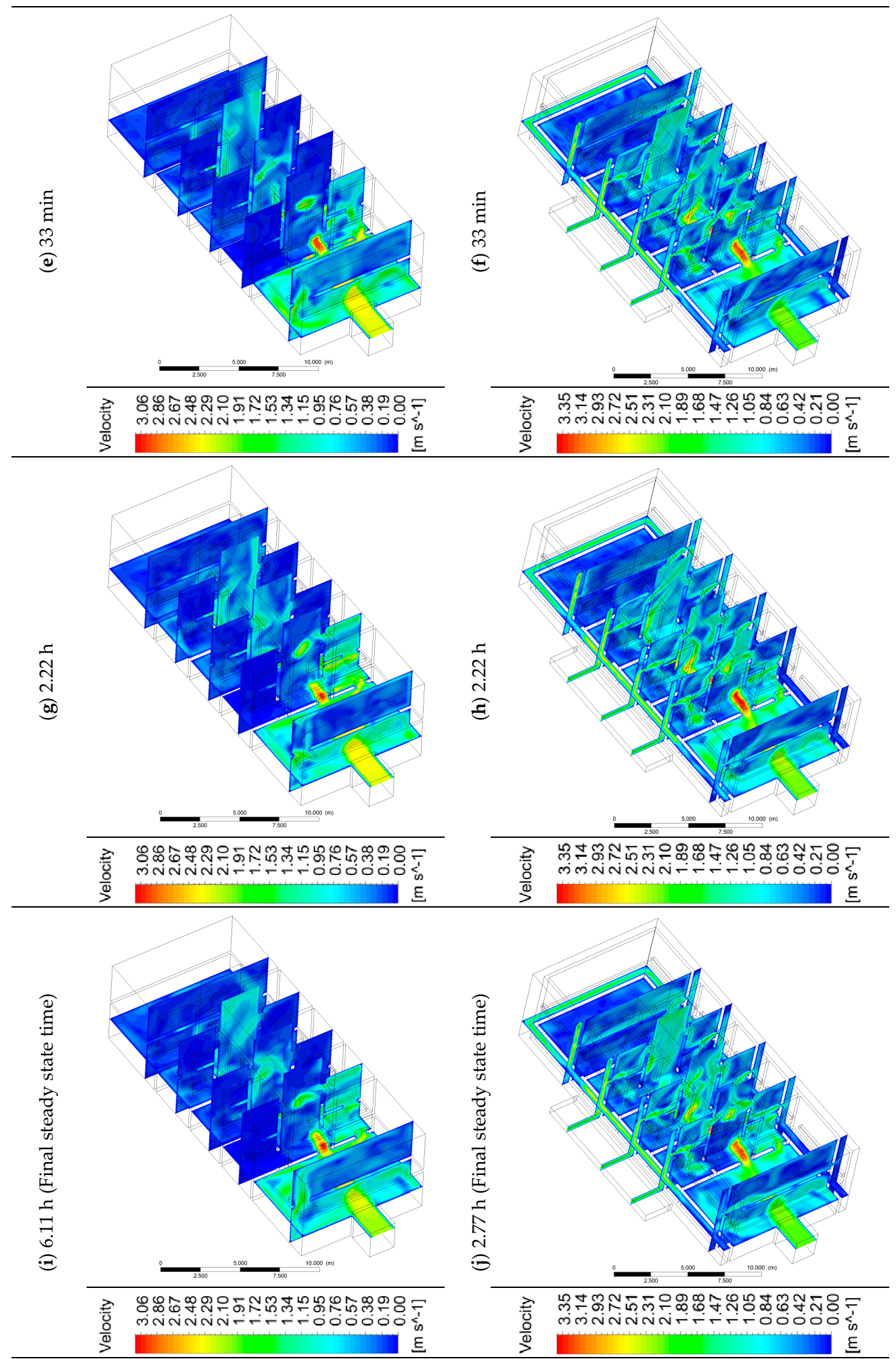

Figure 12. Comparison of ventilation time between natural ventilation and new system (without WHR). (a) 4 min of natural ventilation; (b) 4 min of cold lane system ventilation (without WHR); (c) 16 min of natural ventilation; (d) 16 min of cold lane system ventilation (without WHR); (e) 33 min of natural ventilation; (f) 33 min of cold lane system ventilation (without WHR); (g) $2.22 \mathrm{~h}$ of natural ventilation; (h) $2.22 \mathrm{~h}$ of cold lane system ventilation (without WHR); (i) $6.11 \mathrm{~h}$ (Final steady state time); (j) $2.77 \mathrm{~h}$ (Final steady state time). 
This section mainly discusses the time it takes for the building's natural ventilation and cooling system to reach a steady state without considering the thermal radiation of the wall or the steady-state indoor temperature, and compares the cooling and ventilation efficiency of the two methods. However, in summer, the surface of the building is exposed to a lot of solar radiation for a long time, resulting in a much higher outer surface temperature than the normal outdoor air temperature. The wall becomes the medium for heat conduction, which makes the indoor wall temperature another important factor affecting the indoor temperature. In the next section, we mainly discuss the differences between the new ventilation and cooling system with and without WHR.

\subsection{Comparison of System with and without WHR}

\subsubsection{Cooling Time and Final Equilibrium Temperature}

Based on previous climate analyses of the study subject's region, we selected a day to measure the building's outer surface, inner surface, and room temperature during the period with the highest solar radiation in summer, as shown in Figure 13. It can be seen from the figure that from 01:00 to 09:00, the three temperature values were not much different. However, from 10:00 to 21:00, with increased solar radiation, the temperature of the outer surface of the building rose very fast, reaching a peak of $61.1^{\circ} \mathrm{C}$ at 15:00. After the temperature was transmitted into the room through the wall, it also affected the indoor temperature. As heat transfer takes a certain amount of time, the temperature of the indoor wall did not reach its peak until 16:00. The maximum indoor wall temperature was $38.6^{\circ} \mathrm{C}$, and the maximum indoor temperature was $37.1^{\circ} \mathrm{C}$.

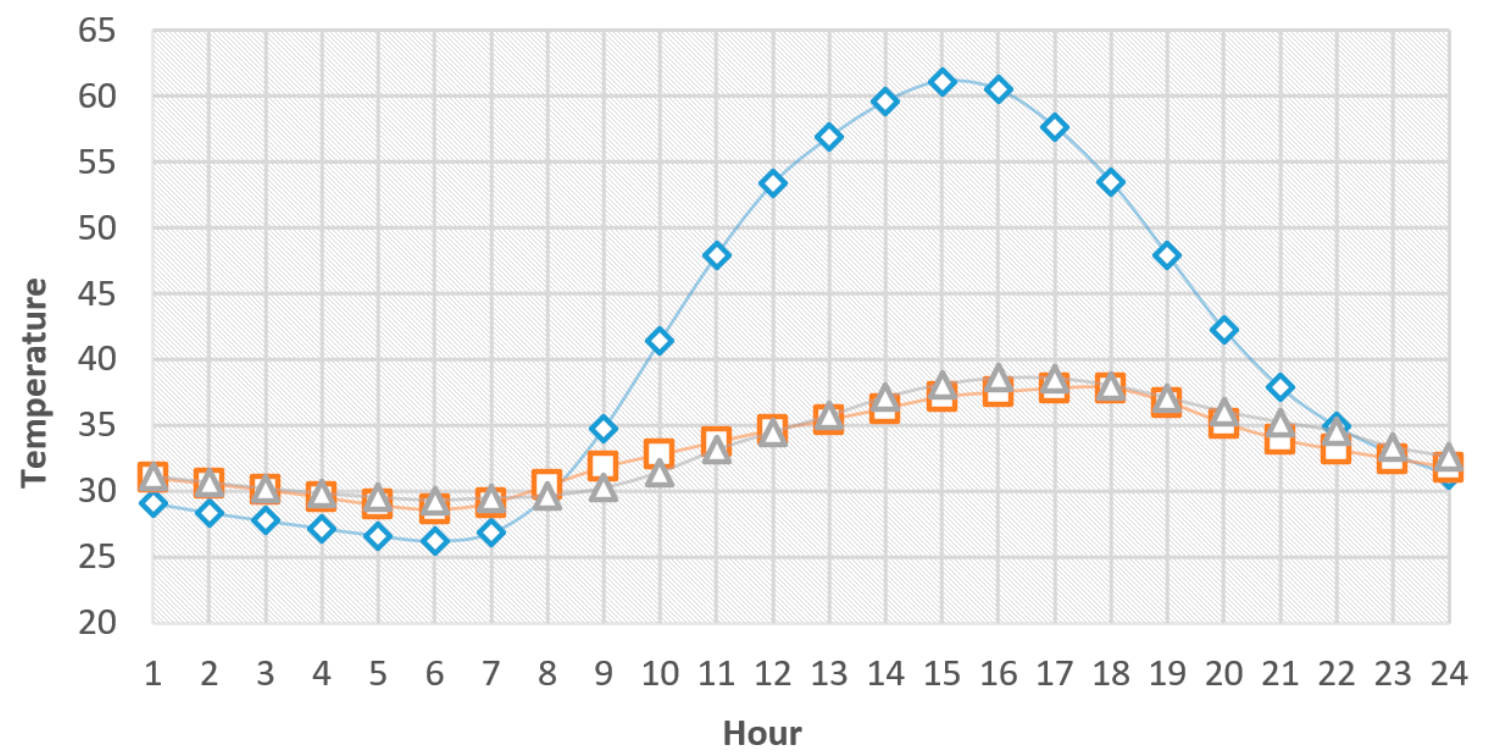

\section{$\diamond$ Outer wall temperature $-\square-$ Inner wall temperature $-\Delta$ Room temperature}

Figure 13. Contrast of outer wall with indoor wall temperature and indoor temperature.

Figure 14 shows the comparison between ventilation with and without WHR based on the cold lane ventilation and cooling system. After $16 \mathrm{~min}$ of ventilation (Figure 14d), the cold air from the cold lane entered the three rooms on the second floor, and the temperature drop rate of these three rooms was still the fastest. However, when the cold air continued to travel along the wall by the new system, it was gradually heated under the influence of the inherent temperature of the wall. As a result, before the cold air reached other rooms, the temperature was the same as the indoor wall temperature, thus affecting the cooling efficiency of the new system. Similarly, without WHR, the cooling efficiency 
was much higher at $16 \mathrm{~min}$ (Figure 14c). At $33 \mathrm{~min}$, the difference was even more pronounced; in the building without WHR (Figure 10e), the indoor temperature on the far side of the building away from the cold lane dropped to about $30^{\circ} \mathrm{C}$. In the building with WHR (Figure 14f), the room temperature was about $32{ }^{\circ} \mathrm{C}$.

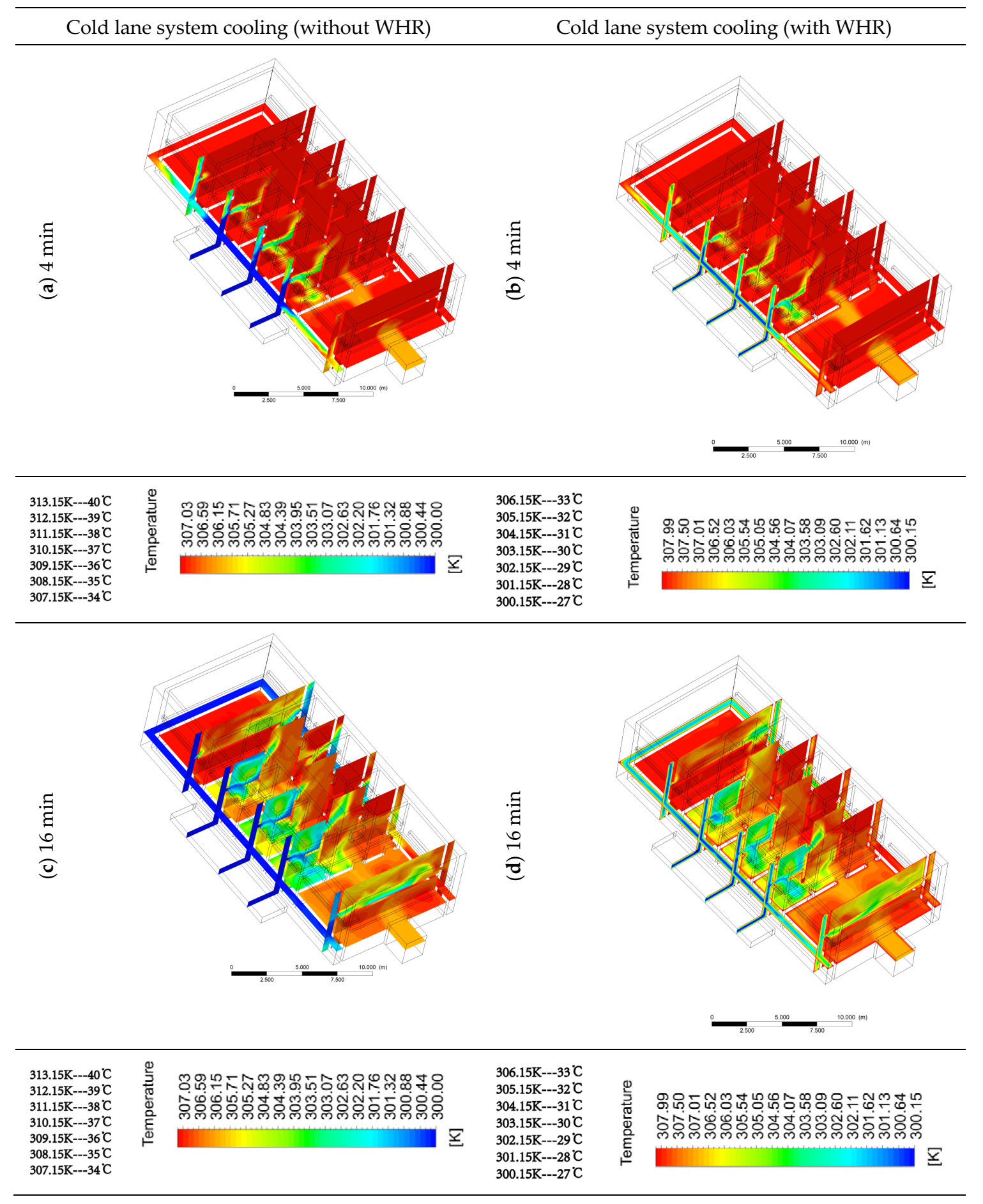

Figure 14. Cont. 

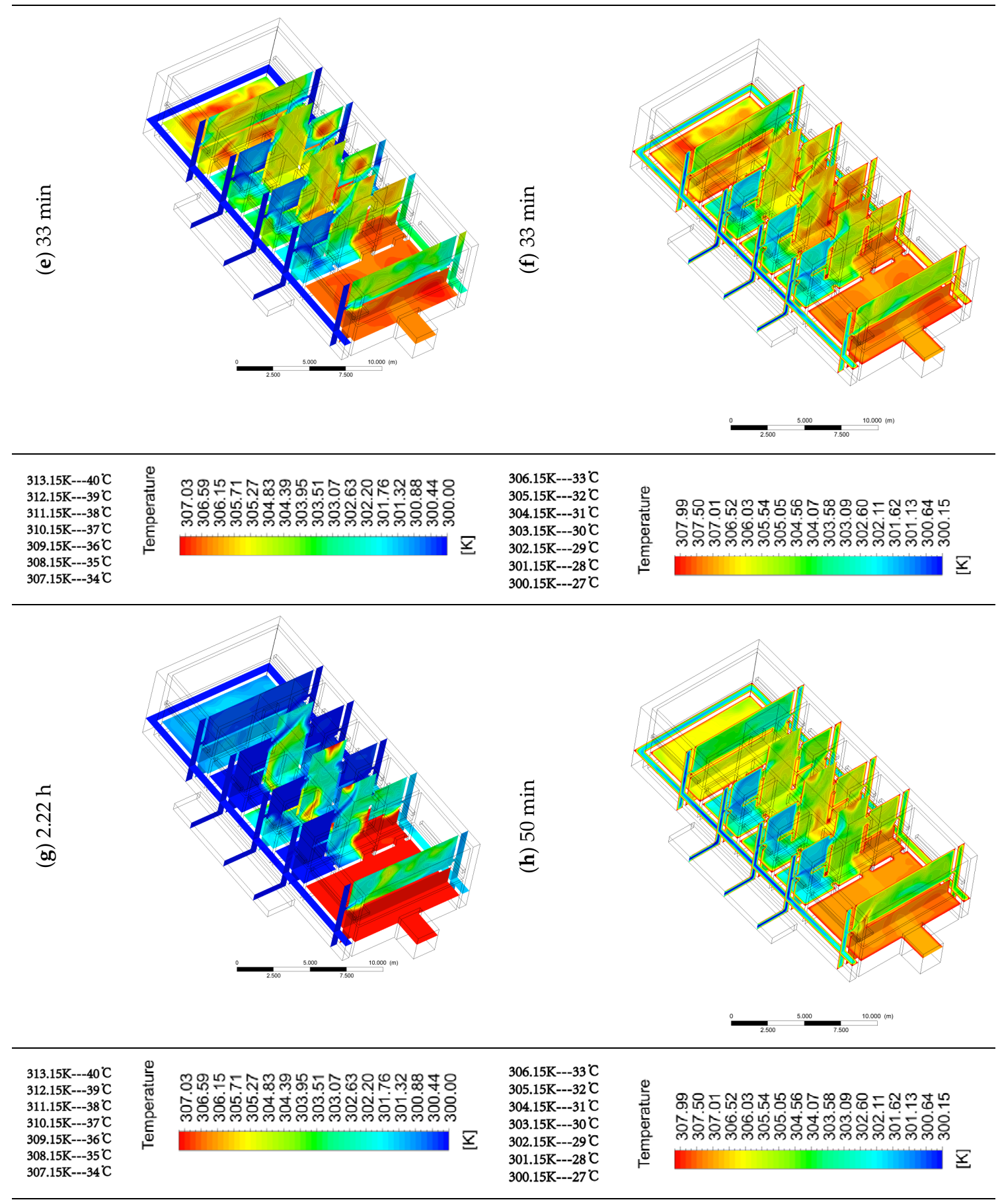

Figure 14. Cont. 


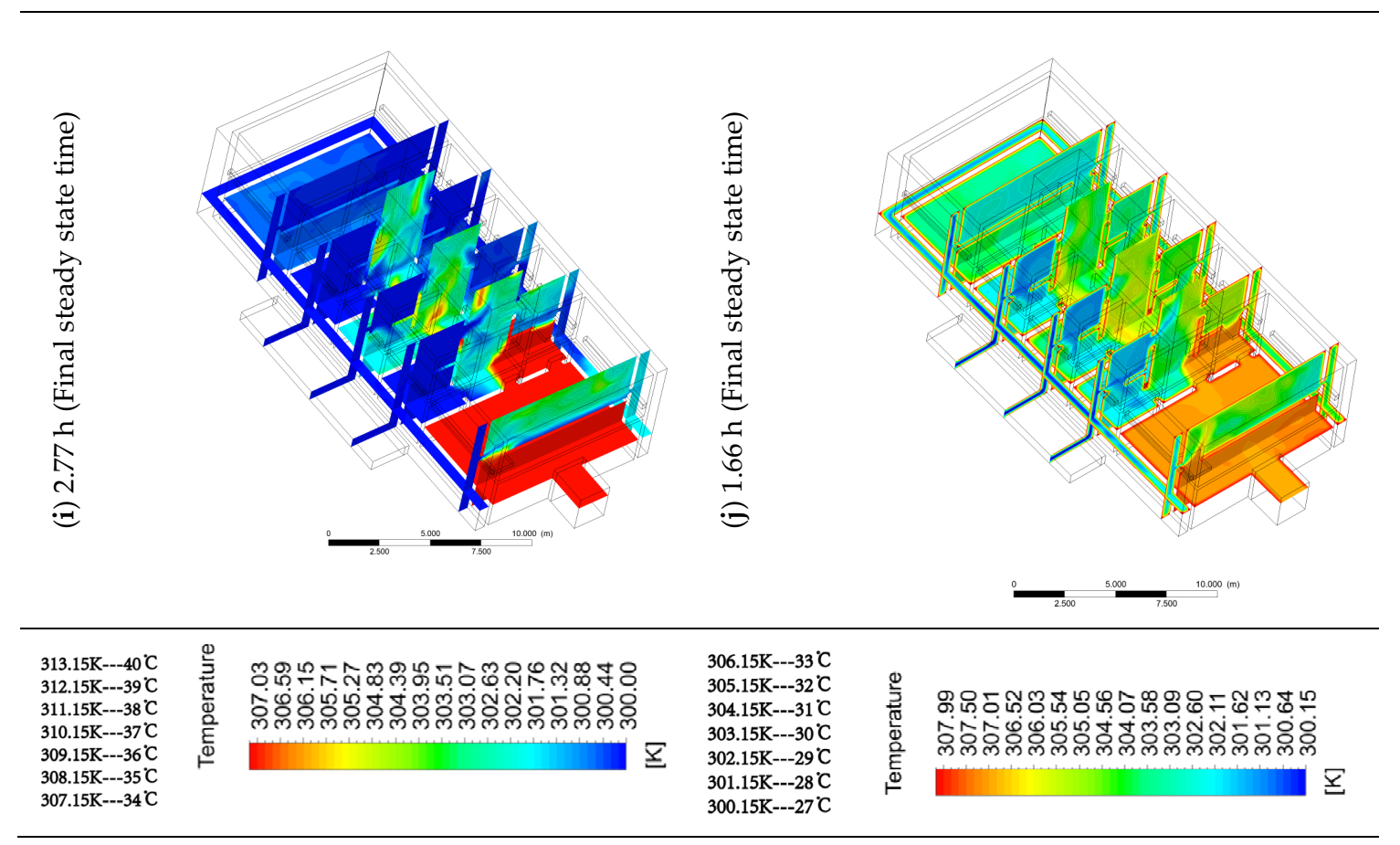

Figure 14. Comparison of cooling time of new system under conditions with and without WHR. (a) 4 min of cold lane system cooling (without WHR); (b) 4 min of cold lane system cooling (with WHR);

(c) $16 \mathrm{~min}$ f cold lane system cooling (without WHR); (d) 16 min of cold lane system cooling (with WHR);

(e) 33 min of cold lane system cooling (without WHR); (f) 33 min of cold lane system cooling (with WHR);

(g) $2.22 \mathrm{~h}$ of cold lane system cooling (without WHR); (h) 50 min cold lane system cooling (with WHR);

(i) $2.77 \mathrm{~h}$ (Final steady state time); (j) $1.66 \mathrm{~h}$ (Final steady state time).

Under ideal conditions, i.e., without WHR, if cold air is continuously injected into the interior of the building, the indoor air temperature will be equal to the temperature of the incoming cold air over a period of time, but in fact, this will not happen. When the building has thermal wall radiation, the wall can be regarded as a fixed heat source. The continuously imported cold air will also be heated by the wall after it reaches the room, and the heat exchange will not stop until it is equal to the temperature of the surrounding air. Therefore, it takes less time for the room temperature in the building to reach the equilibrium point than it does without WHR, and the temperature at the equilibrium point is also higher than that without WHR. Although the efficiency is reduced, this is closer to the actual situation and the simulation results are more reliable. In previous studies, it was found that when Fluent was used for simulation, few people considered the thermal radiation of the wall, which has a great impact on the calculation of air-conditioning energy consumption and the cooling load of buildings in the later period. Without WHR, the temperature of all rooms in the building reached $28{ }^{\circ} \mathrm{C}$ after $2.22 \mathrm{~h}$ (Figure 14j), and the cooling effect of the cold air continued to reach equilibrium temperature (Figure 14i) after $6.11 \mathrm{~h}$. In the building with WHR, at $50 \mathrm{~min}$ (Figure 14h), the temperature of all rooms no longer dropped significantly, and finally reached equilibrium (Figure $14 \mathrm{j}$ ) after $1.66 \mathrm{~h}$. The temperature was maintained at about $30-32{ }^{\circ} \mathrm{C}$, and the cooling efficiency was $2.44{ }^{\circ} \mathrm{C} / \mathrm{h}$. Although the cooling efficiency per unit time was improved, this was due to the shorter time to reach the equilibrium temperature. The time for the two to reach the equilibrium point differed by $1.11 \mathrm{~h}$, and the equilibrium temperature after the cooling of the room differed by $2-4{ }^{\circ} \mathrm{C}$. It also contains the deviation between the amount of cooling load reduction, which will be further explained in future studies. 


\subsubsection{Cold Lane System Ventilation}

Figure 15 shows the ventilation effect of buildings with and without WHR. Under the effect of the cold lane ventilation and cooling system, the whole building formed overall air circulation after 4 min of ventilation (Figure 15a,b), the air flow rate was fast everywhere, and the movement trend was relatively active. It can be concluded that the heat conduction velocity of air has nothing to do with the air flow velocity. The ventilation status in the building at $4 \mathrm{~min}$ was not much different from that at $6.11 \mathrm{~h}$ (Figure 15i,j), but there was a big difference in heat exchange efficiency.

\subsection{Suitable Amount of Time to Use the New System}

The new system with and without WHR has a large impact on cooling efficiency, cooling time, final heat balance point temperature, and reduced cooling load. In this study, we estimated the suitable amount of time to use the cold lane ventilation and cooling system throughout the year with and without WHR, the room temperature after using the new system, and the amount of reduced cooling load.

Figure 16 shows the appropriate amount of time to use the new system in the area where the study case is located. Without WHR, it is suitable to use the system for $2036 \mathrm{~h}$ throughout the year, accounting for $23.24 \%$ of the total time. The time with WHR is $2019 \mathrm{~h}$, accounting for $23.04 \%$ of the year. The difference between the two is $17 \mathrm{~h}$, and the annual proportion difference is $0.2 \%$.

\subsection{Total Amount of Cooling Load Reduced by the New System}

Figure 17 shows the cooling load reduction in the building after using the system throughout the year. Without WHR, the cooling load reduction for the year is $4786.494 \mathrm{~kW} \cdot \mathrm{h}$, and with WHR, the annual reduction is $2989.128 \mathrm{~kW} \cdot \mathrm{h}$, a difference of $1797.336 \mathrm{~kW} \cdot \mathrm{h}$.

\subsection{Indoor Temperature Above $28^{\circ} \mathrm{C}$}

Figure 18 shows the change of indoor temperature during the natural ventilation and cooling of the building with and without WHR. Combined with local meteorological conditions, $28^{\circ} \mathrm{C}$ is used as the limit of passive indoor cooling, and the amount of time when the temperature exceeds $28^{\circ} \mathrm{C}$ throughout the year is counted. In the case of natural ventilation and cooling, the temperature exceeds $28{ }^{\circ} \mathrm{C}$ for $2062 \mathrm{~h}$, accounting for $23.53 \%$ of the annual amount. Using the new system without WHR, the room temperature exceeds $28^{\circ} \mathrm{C}$ for $1863 \mathrm{~h}$ ( $199 \mathrm{~h}$ less than with natural ventilation), accounting for $21.26 \%$ of the year. Using the new system with WHR, the temperature exceeds $28{ }^{\circ} \mathrm{C}$ for $1966 \mathrm{~h}$ ( $96 \mathrm{~h}$ less than with natural ventilation), accounting for $22.44 \%$ of the annual total. 


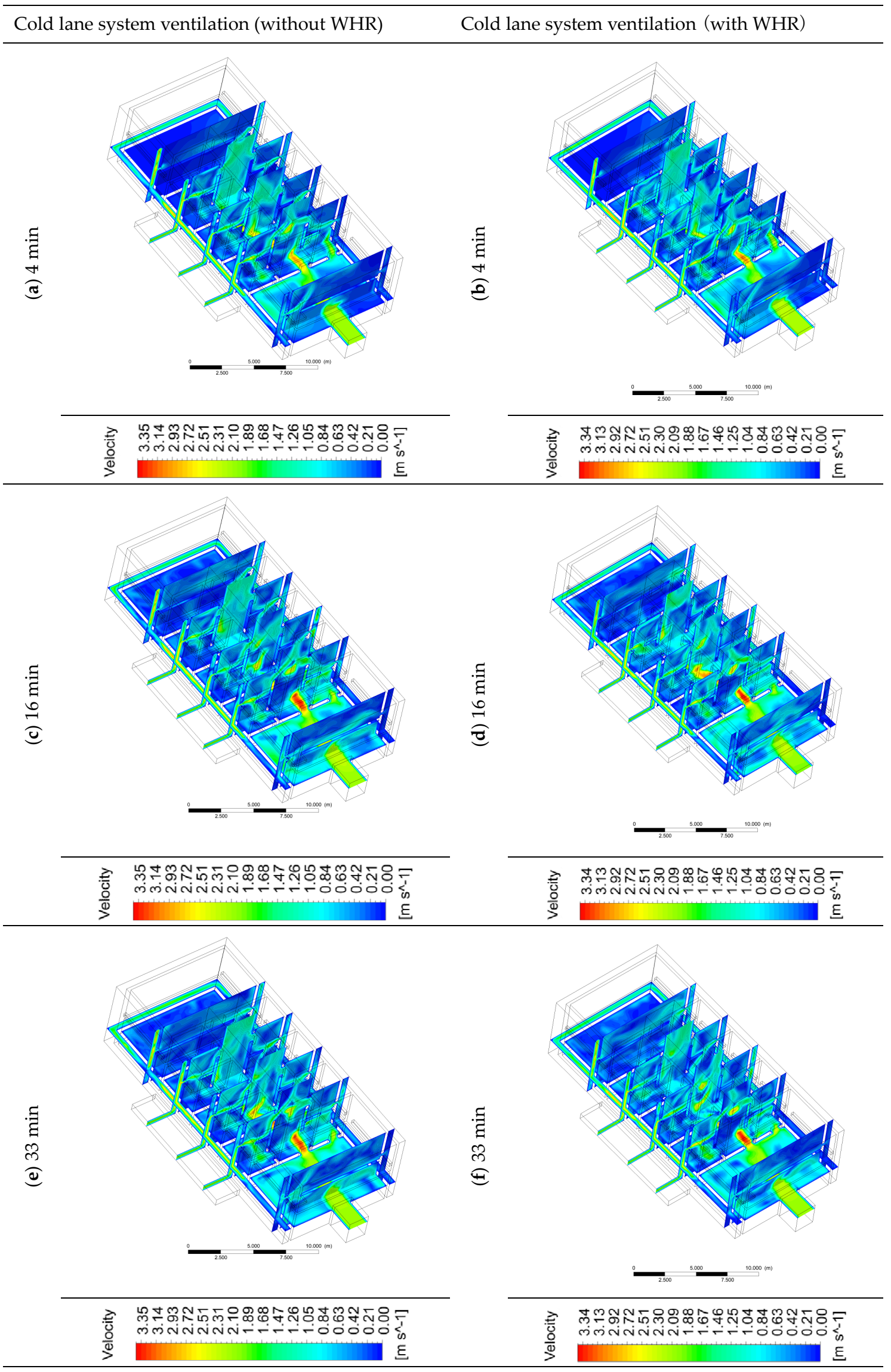

Figure 15. Cont. 


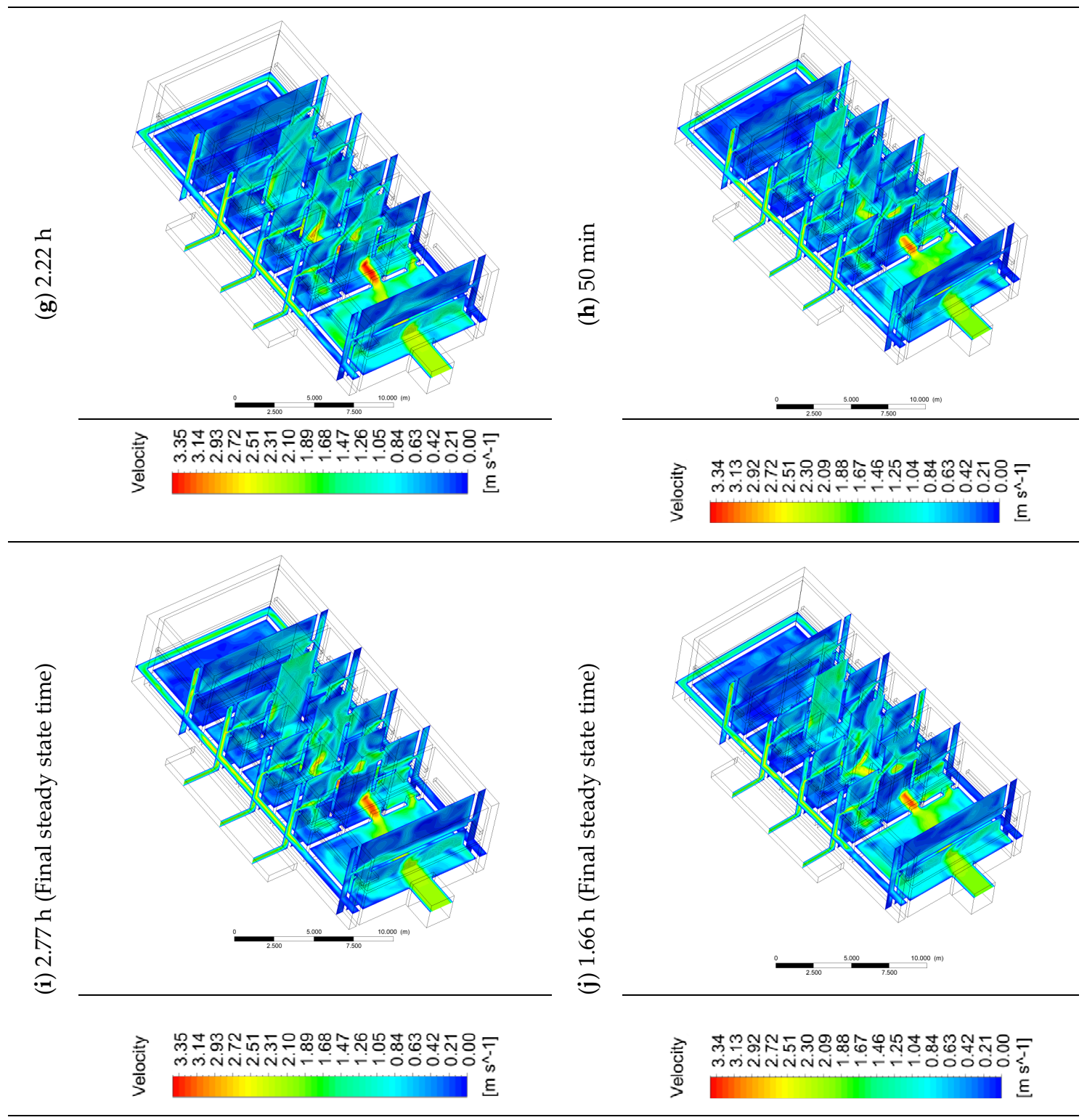

Figure 15. Comparison of ventilation time of new system with and without WHR. (a) 4 min of cold lane system ventilation (without WHR); (b) 4 min of cold lane system cooling (with WHR); (c) 16 min of cold lane system ventilation (without WHR); (d) 16 min of cold lane system cooling (with WHR); (e) $33 \mathrm{~min}$ of cold lane system ventilation (without WHR); (f) $33 \mathrm{~min}$ of cold lane system cooling (with WHR); (g) $2.22 \mathrm{~h}$ of cold lane system ventilation (without WHR); (h) 50 min cold lane system cooling (with WHR); (i) $2.77 \mathrm{~h}$ (Final steady state time); (j) $1.66 \mathrm{~h}$ (Final steady state time). 


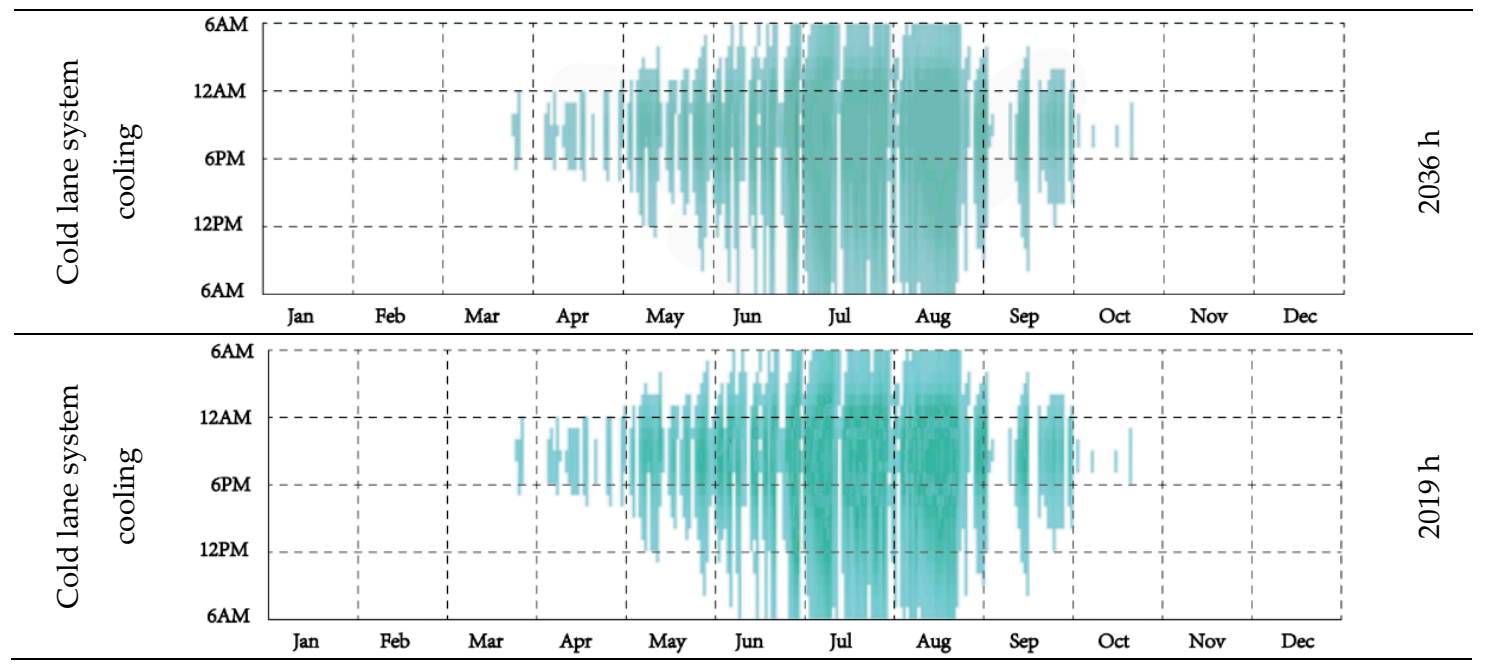

Figure 16. Comparison of new system's annual available time with and without WHR.

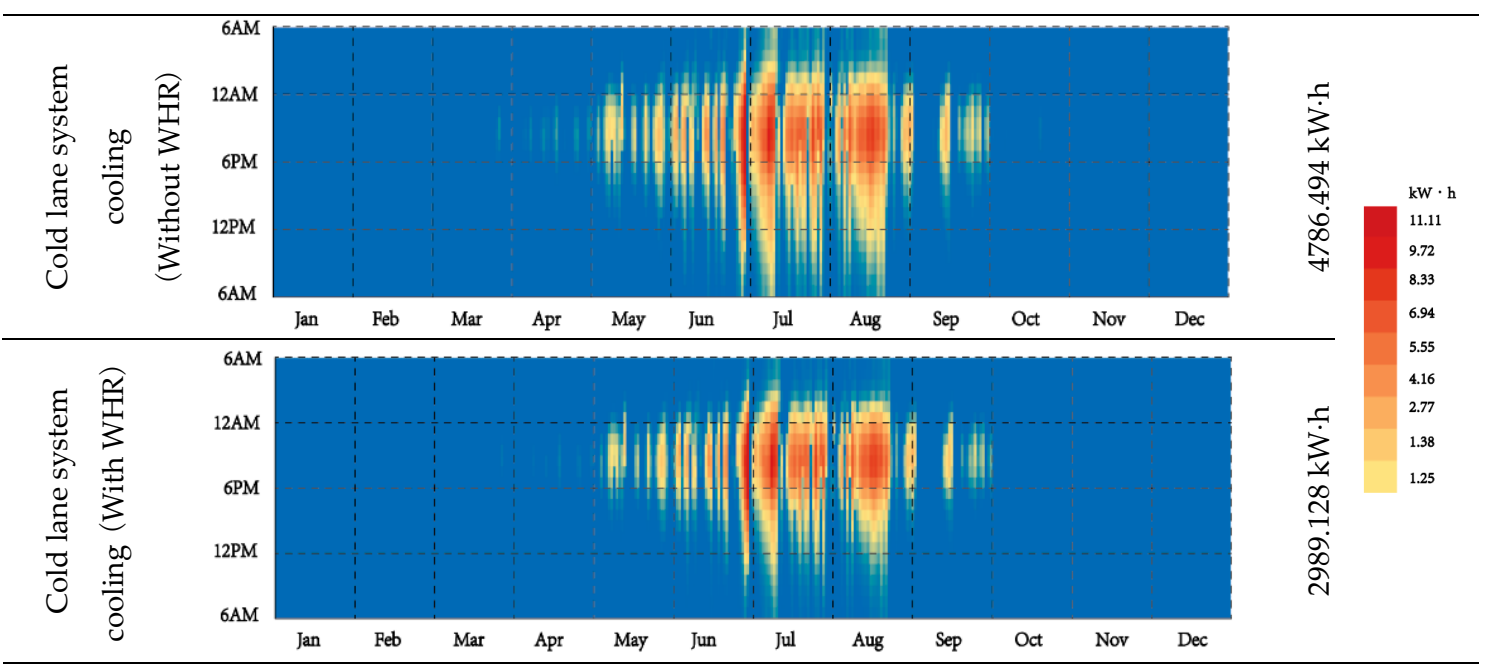

Figure 17. Comparison of annual cooling load reduction in new system with and without WHR. 


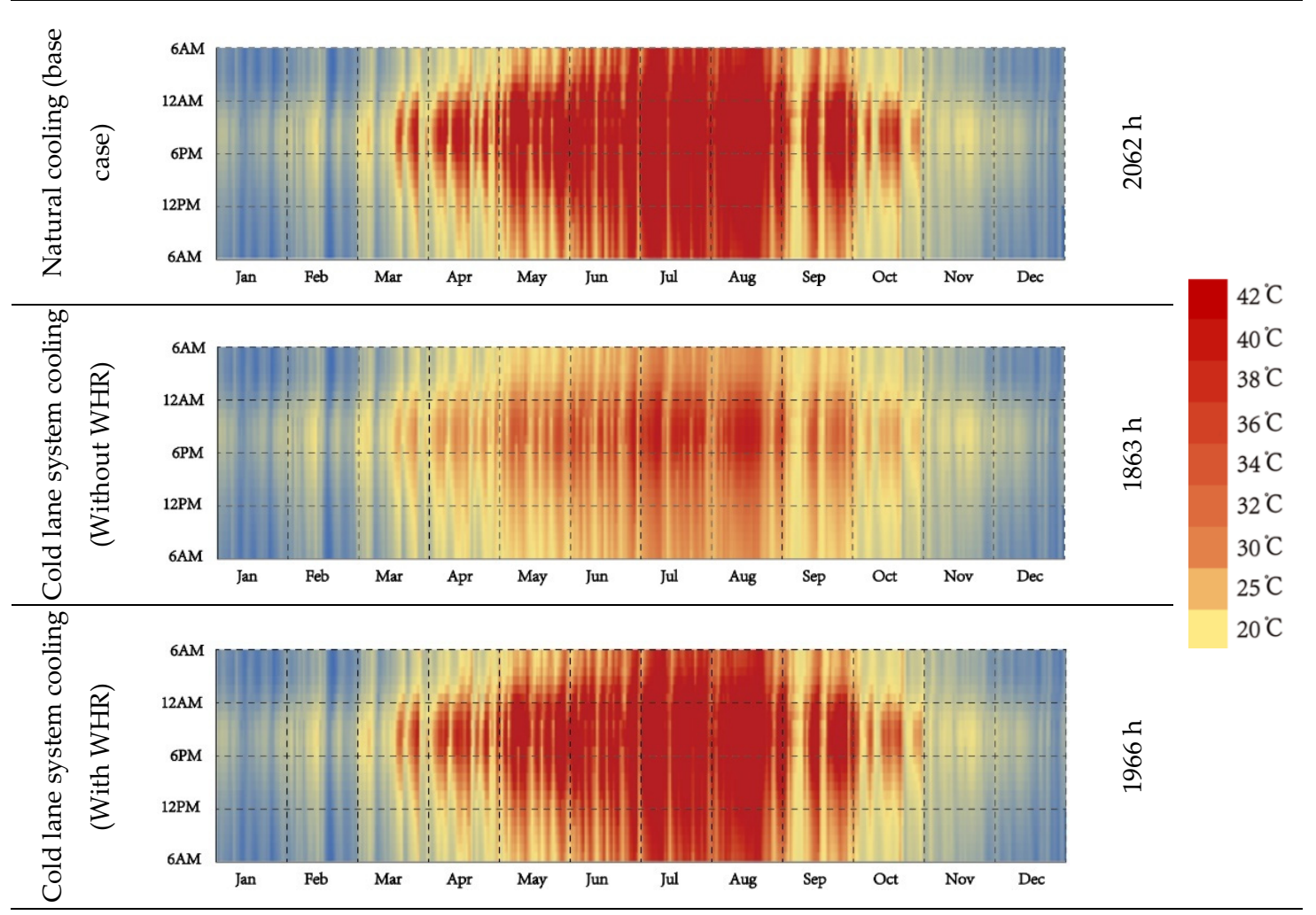

Figure 18. Comparison of time when annual average building temperature exceeds $28{ }^{\circ} \mathrm{C}$ under the three conditions.

\subsection{Building Repair}

The function expansion and transformation of traditional residential buildings reflects the concept of sustainable development, and it is necessary to take into account the protection of building value and reasonable development and utilization. Passive energy-saving renovation will inevitably cause a certain degree of damage to the original shape and internal structure of the building. Therefore, the reconstruction process should follow a reasonable concept of traditional residential protection, and redesign with local cultural elements. On the basis of improving the quality of living, it has also become the easiest and most direct way to express traditional regional culture. The following protection measures are proposed for the problem:

- For building renovation, the functions of buildings in the village should be established and be divided into exhibition and residential buildings. Exhibition buildings represent the entire village architecture, which contains historical information, architectural modeling, unique decorative arts, and a technical level of construction. Therefore, this type of building is not suitable for renovation, and its main purpose is to convey information. On the contrary, for residential buildings, more attention should be paid to living comfort and sustainable utilization, and this type of building is suitable for passive transformation.

- The location factors of buildings should be analyzed to decide whether to reform them. It is necessary to learn more about the traffic conditions of the village, including the density and flow of people and accessibility. Buildings on both sides of representative streets are not suitable for renovation, because such streets represent the overall style and regional characteristics of the village. Moreover, the large scale of the main road and surrounding streets also limits the formation of cold lanes. On the contrary, residential areas located deep in the village have relatively low requirements for viewing, and usability is more important to them. 
- The introduction of new functions should be carried out under the transformation principle of being identifiable. It should be based on the premise of continuing and inheriting the characteristic elements of traditional architecture as much as possible. Design and construction, which draw on traditional structures and construction practices, are essentially modern and adaptable expressions of traditional residential construction, reflecting the respect and inheritance of traditional culture. We need to pay attention to the unity of the whole village; the parts that are in direct view should be repaired strictly in accordance with the local characteristic style, such as the roofs of buildings. In this study, the new system mainly relied on the external walls of residential buildings for renovation, and the walls were easily blocked by surrounding buildings, which would reduce the damage to the village's characteristics.

\section{Conclusions and Future Research}

\subsection{Conclusions}

This research was oriented to traditional residential buildings in Shuhe, Ankang, Shaanxi Province, with the goal of using passive ventilation and cooling in summer. Taking advantage of the characteristic that the average temperature in cold lanes is lower than the ordinary outdoor temperature, cold air was introduced into the interior through the new system, in order to reduce the indoor temperature and improve the ventilation efficiency. First, a new system was designed and compared with natural ventilation cooling. Subsequently, the influence of wall heat radiation on indoor temperature was discussed in detail, with an analysis of the corresponding cooling time, cooling efficiency, ventilation efficiency, and amount of cooling load with and without WHR. It is proved that wall heat radiation has a great influence on indoor temperature, cooling time, cooling efficiency, and reduced cooling load, but has little effect on the ventilation efficiency of the courtyard. The detailed conclusion is as follows:

- When cooling by natural ventilation, the overall building temperature stabilized after $6.11 \mathrm{~h}$, the average temperature after stabilization was $34^{\circ} \mathrm{C}$, and the cooling efficiency was $0.16^{\circ} \mathrm{C} / \mathrm{h}$. After using the cold lane ventilation and cooling system, the overall building temperature stabilized after $2.77 \mathrm{~h}$ without WHR, the stable temperature was $29^{\circ} \mathrm{C}$, and the cooling efficiency was $1.81^{\circ} \mathrm{C} / \mathrm{h}$. With WHR, the temperature stabilized after $1.66 \mathrm{~h}$, the average temperature after stabilization was $32^{\circ} \mathrm{C}$, and the cooling efficiency was $2.4^{\circ} \mathrm{C} / \mathrm{h}$.

- After using the cold lane ventilation and cooling system, the ventilation time of the building was reduced from 33 to $4 \mathrm{~min}$, which proves that the indoor heat exchange rate does not change with the change of air flow rate.

- Based on the absence of wall heat radiation, the amount of time to use the cooling system throughout the year is given. Without WHR, the system can be used for $2036 \mathrm{~h}$ throughout the year, accounting for $23.24 \%$ of the annual time, and with WHR, the time is $2019 \mathrm{~h}$, accounting for $23.04 \%$ of the year (a 17-h difference). Under the condition of natural ventilation, the amount of time exceeding $28^{\circ} \mathrm{C}$ in a year is $2062 \mathrm{~h}$, and after using this system, without WHR the amount of time exceeding $28^{\circ} \mathrm{C}$ in a year is $1863 \mathrm{~h}$, accounting for $21.23 \%$ of the whole year, which is a $199-\mathrm{h}$ difference. With WHR, the amount of time exceeding $28^{\circ} \mathrm{C}$ in a year is $1966 \mathrm{~h}$, accounting for $22.44 \%$ of the annual total, which is a $96-\mathrm{h}$ difference from natural ventilation. After using this system, without considering wall heat radiation, the annual cooling load reduction in the entire courtyard is $4786.494 \mathrm{~kW} \cdot \mathrm{h}$, and with wall heat radiation considered, the annual reduction is $2989.128 \mathrm{~kW} \cdot \mathrm{h}$, a difference of $1797.336 \mathrm{~kW} \cdot \mathrm{h}$.

\subsection{Future Research}

However, there are still some important issues that need to be discussed in the future, including the following: 
- This research needs to be verified in actual operation. The detailed renovation design of buildings will be the focus of future research. It will consider the heat insulation and air-tightness of the materials, minimizing changes to the original building shape, and retaining the unique regional characteristics of traditional buildings.

- Based on the completely passive cooling of the cold lane system, $28{ }^{\circ} \mathrm{C}$ is the lowest possible indoor temperature, which still does not meet the standard temperature for human thermal comfort. Future research should consider the energy-saving value of air-conditioning when the air-conditioning and cold lane cooling system are combined to reach the standard comfort range.

- Cold lanes not only can reduce the air temperature but also have the function of local moistening. Future research will consider indoor air humidity as a reference value to judge the comfort of indoor living.

- Setting up shading equipment on windows or patios can be considered, and the change characteristics of indoor temperature and ventilation as well as the reduction in light and cooling load in the room with a combination of shading and cold lane systems can be discussed.

Author Contributions: Conceptualization, X.Y.; methodology, X.Y., B.J.D.; software, X.Y., Y.G.; investigation, S.H., J.X.; formal analysis, X.Y., B.J.D.; writing—original draft preparation, Y.G.; writing-review and editing, X.Y., B.J.D.; supervision, X.Y. All authors have read and agreed to the published version of the manuscript.

Funding: This research was funded by the National Science Foundation of China, grant number 51978058, and by Major Theoretical and Practical Problems of Social Science in Shaanxi Province, grant number $2020 Z 381$.

Acknowledgments: The authors thank the professors and students at the University of Kitakyushu, as well as Xidian University and Chang'an University, for their generous help with the full paper from investigation to the checking process.

Conflicts of Interest: The authors declare no conflict of interest.

\section{References}

1. Agencia Internacional de la Energía. World Energy Outlook 2017; Int ENERGY AGENCY Together Secur Sustain 2017; OECD: London, UK, 2017. [CrossRef]

2. IEA Online Data Services. Available online: https://www.iea.org/subscribe-to-data-services/world-energybalances-and-statistics (accessed on 15 July 2020).

3. U.S. EIA. Annual Energy Outlook 2018; DOE: Washington, DC, USA, 2018.

4. Rhodes, C.J. The 2015 Paris Climate Change Conference: Cop21. Sci. Prog. 2016, 99, 97-104. [CrossRef] [PubMed]

5. The Guardian. Available online: https://www.theguardian.com/environment/2015/oct/26/cold-economycop21-global-warming-carbon-emissions (accessed on 26 October 2015).

6. Japan Refrigeration and Air Conditioning Industry Association (JRAIA). World Air Conditioner Demand by Region; JRAIA: ku-Minato, Japan, 2017.

7. Tsinghua University Annual Report on China Building Energy Efficiency; China Architecture \& Building Press: Beijing, China, 2017.

8. International Energy Agency Transition to Sustainable Buildings: Strategies and Opportunities to 2050; OECD/IEA: Paris, France, 2013.

9. Mi, Z.; Zheng, J.; Meng, J.; Shan, Y.; Zheng, H.; Ou, J.; Guan, D.; Wei, Y.-M. China's Energy Consumption in the New Normal. Earths Future 2018, 6, 1007-1016. [CrossRef]

10. Liu, C.; Xu, W.; Li, A.; Sun, D.; Huo, H. Energy balance evaluation and optimization of photovoltaic systems for zero energy residential buildings in different climate zones of China. J. Clean. Prod. 2019, 235, 1202-1215. [CrossRef]

11. Liu, Z.; Liu, Y.; He, B.-J.; Xu, W.; Jin, G.; Zhang, X. Application and suitability analysis of the key technologies in nearly zero energy buildings in China. Renew. Sustain. Energy Rev. 2019, 101, 329-345. [CrossRef]

12. Chi, F.; Xu, L.; Peng, C. Integration of completely passive cooling and heating systems with daylighting function into courtyard building towards energy saving. Appl. Energy 2020, 266, 114865. [CrossRef]

13. Tahsildoost, M.; Zomorodian, Z. Energy, carbon, and cost analysis of rural housing retrofit in different climates. J. Build. Eng. 2020, 30, 101277. [CrossRef] 
14. He, B.-J.; Yang, L.; Ye, M.; Mou, B.; Zhou, Y. Overview of rural building energy efficiency in China. Energy Policy 2014, 69, 385-396. [CrossRef]

15. Ding, J.; Ma, S. Comparative analysis of habitation behavioral patterns in spatial configuration of traditional houses in Anhui, Jiangsu, and Zhejiang provinces of China. Front. Arch. Res. 2020, 9, 54-66. [CrossRef]

16. Merzoug, W.; Chergui, S.; Zouaoui, M.C. The impact of reinforced concrete on the modern-day architectural heritage of Algeria. J. Build. Eng. 2020, 30, 101210. [CrossRef]

17. Andreescu, I.; Gaivoronsch, V.; Mosoarca, M. Old and New-The Complex Problem of Integrating New Functions into Old Building. Procedia Eng. 2016, 161, 1103-1108. [CrossRef]

18. Bady, M.; Kato, S.; Takahashi, T.; Huang, H. An experimental investigation of the wind environment and air quality within a densely populated urban street canyon. J. Wind. Eng. Ind. Aerodyn. 2011, 99, 857-867. [CrossRef]

19. Chen, G.; Wang, D.; Wang, Q.; Li, Y.; Wang, X.; Hang, J.; Gao, P.; Ou, C.; Wang, K. Scaled outdoor experimental studies of urban thermal environment in street canyon models with various aspect ratios and thermal storage. Sci. Total. Environ. 2020, 726, 138147. [CrossRef] [PubMed]

20. Ai, Z.; Mak, C. Wind-induced single-sided natural ventilation in buildings near a long street canyon: CFD evaluation of street configuration and envelope design. J. Wind. Eng. Ind. Aerodyn. 2018, 172, 96-106. [CrossRef]

21. Allegrini, J. A wind tunnel study on three-dimensional buoyant flows in street canyons with different roof shapes and building lengths. Build. Environ. 2018, 143, 71-88. [CrossRef]

22. Hadavi, M.; Pasdarshahri, H. Quantifying impacts of wind speed and urban neighborhood layout on the infiltration rate of residential buildings. Sustain. Cities Soc. 2020, 53, 101887. [CrossRef]

23. Toe, D.H.C.; Kubota, T. Comparative assessment of vernacular passive cooling techniques for improving indoor thermal comfort of modern terraced houses in hot-humid climate of Malaysia. Sol. Energy 2015, 114, 229-258. [CrossRef]

24. Dabaieh, M.; Serageldin, A.A. Earth air heat exchanger, Trombe wall and green wall for passive heating and cooling in premium passive refugee house in Sweden. Energy Convers. Manag. 2020, 209, 112555. [CrossRef]

25. Dili, A.; Naseer, M.; Varghese, T.Z. Passive control methods of Kerala traditional architecture for a comfortable indoor environment: A comparative investigation during winter and summer. Build. Environ. 2010, 45, 1134-1143. [CrossRef]

26. Ding, G.; Ying, X. Embodied and operating energy assessment of existing buildings—Demolish or rebuild. Energy 2019, 182, 623-631. [CrossRef]

27. Xu, J.; Lu, Z.; Gao, W.; Yang, M.; Su, M. The comparative study on the climate adaptability based on indoor physical environment of traditional dwelling in Qinba mountainous areas, China. Energy Build. 2019, 197, 140-155.

28. Zhang, L.; Hou, Y.; Liu, Z.; Du, J.; Xu, L.; Zhang, G.; Shi, L. Trombe wall for a residential building in Sichuan-Tibet alpine valley-A case study. Renew. Energy 2020, 156, 31-46. [CrossRef]

29. Mitterboeck, M.; Korjenic, A. Analysis for improving the passive cooling of building's surroundings through the creation of green spaces in the urban built-up area. Energy Build. 2017, 148, 166-181. [CrossRef]

30. Kubilay, A.; Derome, D.; Carmeliet, J. Impact of evaporative cooling due to wetting of urban materials on local thermal comfort in a street canyon. Sustain. Cities Soc. 2019, 49, 101574. [CrossRef]

31. Allegrini, J.; Dorer, V.; Carmeliet, J. Influence of the urban microclimate in street canyons on the energy demand for space cooling and heating of buildings. Energy Build. 2012, 55, 823-832. [CrossRef]

32. Allegrini, J.; Dorer, V.; Carmeliet, J. Impact of radiation exchange between buildings in urban street canyons on space cooling demands of buildings. Energy Build. 2016, 127, 1074-1084. [CrossRef]

33. Vallati, A.; Mauri, L.; Colucci, C.; Ocłoń, P. Effects of radiative exchange in an urban canyon on building surfaces' loads and temperatures. Energy Build. 2017, 149, 260-271. [CrossRef]

34. Vallati, A.; Grignaffini, S.; Romagna, M.; Mauri, L.; Colucci, C. Influence of Street Canyon's Microclimate on the Energy Demand for Space Cooling and Heating of Buildings. Energy Procedia 2016, 101, 941-947. [CrossRef]

35. Bijarniya, J.P.; Sarkar, J.; Maiti, P. Environmental effect on the performance of passive daytime photonic radiative cooling and building energy-saving potential. J. Clean. Prod. 2020, 274, 123119. [CrossRef]

36. Syuryavin, A.C.; Park, S.; Nirwono, M.M.; Lee, S.H. Indoor radon and thoron from building materials: Analysis of humidity, air exchange rate, and dose assessment. Nucl. Eng. Technol. 2020, 52, 2370-2378. [CrossRef] 
37. Bhamare, D.K.; Rathod, M.K.; Banerjee, J. Passive cooling techniques for building and their applicability in different climatic zones-The state of art. Energy Build. 2019, 198, 467-490. [CrossRef]

38. Bahgat, R.; Reffat, R.M.; Elkady, S.L. Analyzing the impact of design configurations of urban features on reducing solar radiation. J. Build. Eng. 2020, 101664. [CrossRef]

39. Vaseghi, M.; Fazel, M.; Ekhlassi, A. Numerical investigation of solar radiation effect on passive and active heating and cooling system of a concept museum building. Therm. Sci. Eng. Prog. 2020, 19, 100582. [CrossRef]

40. Taleb, S.; Yeretzian, A.; Jabr, R.A.; Hajj, H. Optimization of building form to reduce incident solar radiation. J. Build. Eng. 2020, 28, 101025. [CrossRef]

41. Chen, F.; Zhang, Y.; Liu, J.; Wang, X.; Chu, P.K.; Chu, B.; Zhang, N. Fly ash based lightweight wall materials incorporating expanded perlite/SiO2 aerogel composite: Towards low thermal conductivity. Constr. Build. Mater. 2020, 249, 118728. [CrossRef]

42. Feng, B.; Tu, J.; Zhang, Y.-H.; Fan, L.-W.; Yu, Z.-T. An improved steady-state method for measuring the thermal contact resistance and bulk thermal conductivity of thin-walled materials having a sub-millimeter thickness. Appl. Therm. Eng. 2020, 171, 114931. [CrossRef]

43. Xu, B.; Xie, X.; Pei, G.; Chen, X.-N. New view point on the effect of thermal conductivity on phase change materials based on novel concepts of relative depth of activation and time rate of activation: The case study on a top floor room. Appl. Energy 2020, 266, 114886. [CrossRef]

44. Khoukhi, M.; Hassan, A.; Abdelbaqi, S. The impact of employing insulation with variant thermal conductivity on the thermal performance of buildings in the extremely hot climate. Case Stud. Therm. Eng. 2019, 16, 100562. [CrossRef]

45. Watanabe, S.; Nagano, K.; Ishii, J.; Horikoshi, T. Evaluation of outdoor thermal comfort in sunlight, building shade, and pergola shade during summer in a humid subtropical region. Build. Environ. 2014, 82, 556-565. [CrossRef]

46. Hoelscher, M.-T.; Nehls, T.; Jänicke, B.; Wessolek, G. Quantifying cooling effects of facade greening: Shading, transpiration and insulation. Energy Build. 2016, 114, 283-290. [CrossRef]

47. Berry, R.; Livesley, S.J.; Aye, L. Tree canopy shade impacts on solar irradiance received by building walls and their surface temperature. Build. Environ. 2013, 69, 91-100. [CrossRef]

48. Zhou, S.; Cui, W.; Zhao, S.; Zhu, S. Operation analysis and performance prediction for a GSHP system compounded with domestic hot water (DHW) system. Energy Build. 2016, 119, 153-163. [CrossRef]

49. Moosavi, L.; Zandi, M.; Bidi, M.; Behroozizade, E.; Kazemi, I. New design for solar chimney with integrated windcatcher for space cooling and ventilation. Build. Environ. 2020, 181, 106785. [CrossRef]

50. McCartney, L.; Orsat, V.; Lefsrud, M.G. An experimental study of the cooling performance and airflow patterns in a model Natural Ventilation Augmented Cooling (NVAC) greenhouse. Biosyst. Eng. 2018, 174, 173-189. [CrossRef]

51. Guo, R.; Gao, Y.; Zhuang, C.; Heiselberg, P.; Levinson, R.; Zhao, X.; Shi, D. Optimization of cool roof and night ventilation in office buildings: A case study in Xiamen, China. Renew. Energy 2020, 147, 2279-2294. [CrossRef]

52. Zuazua-Ros, A.; Ramos, J.C.; Martín-Gómez, C.; Gómez-Acebo, T.; Erell, E. Performance and feasibility assessment of a hybrid cooling system for office buildings based on heat dissipation panels. Energy 2020, 205, 117975. [CrossRef]

53. Lule, I.; Özcan, S.E.; Berckmans, D. Characterisation of ventilation rate in naturally-ventilated buildings using heat dissipation from a line source. Biosyst. Eng. 2014, 124, 53-62. [CrossRef]

54. Sanchez, M.; Lucas, M.; Martinez, P.; Sanchez, A.; Viedma, A. Climatic solar roof: An ecological alternative to heat dissipation in buildings. Sol. Energy 2002, 73, 419-432. [CrossRef]

55. Chen, Q.; Xu, Y.-C. An entransy dissipation-based optimization principle for building central chilled water systems. Energy 2012, 37, 571-579. [CrossRef]

56. Nethaji, N.; Mohideen, T.; Nethaji, M. Energy conservation in room air conditioner unit by recovering cold energy from condensate. Int. J. Refrig. 2019, 104, 95-102. [CrossRef]

57. Ding, Y.; Wei, X.; Wang, Q. Optimization approach of passive cool skin technology application for the Building's exterior walls. J. Clean. Prod. 2020, 256, 120751. [CrossRef]

58. Calautit, J.K.; Tien, P.W.; Wei, S.; Calautit, K.; Hughes, B. Numerical and experimental investigation of the indoor air quality and thermal comfort performance of a low energy cooling windcatcher with heat pipes and extended surfaces. Renew. Energy 2020, 145, 744-756. [CrossRef] 
59. Liu, Z.; Cai, S.; Li, S. Experimental Research on the Temperature Distribution of Natural Displacement Ventilation in the Room under the Influence of Wind Pressure and Air Supply. Procedia Eng. 2017, 205, 989-995. [CrossRef]

60. China's Ministry of Housing and Urban-rural Development. Design Code for Uniform Standards for Civil Building Design; GB50352-2012; China Building Industry Press: Beijing, China, 2019; pp. 119-124.

Publisher's Note: MDPI stays neutral with regard to jurisdictional claims in published maps and institutional affiliations.

(C) 2020 by the authors. Licensee MDPI, Basel, Switzerland. This article is an open access article distributed under the terms and conditions of the Creative Commons Attribution (CC BY) license (http://creativecommons.org/licenses/by/4.0/). 